\title{
Methodology Handbook: Ethnography and Data Analysis
}

The TRANSGANG Team

Carles Feixa, José Sánchez-García, Roger Soler-i-Martí, Eduard Ballesté, Nele Hansen, Adam Brisley

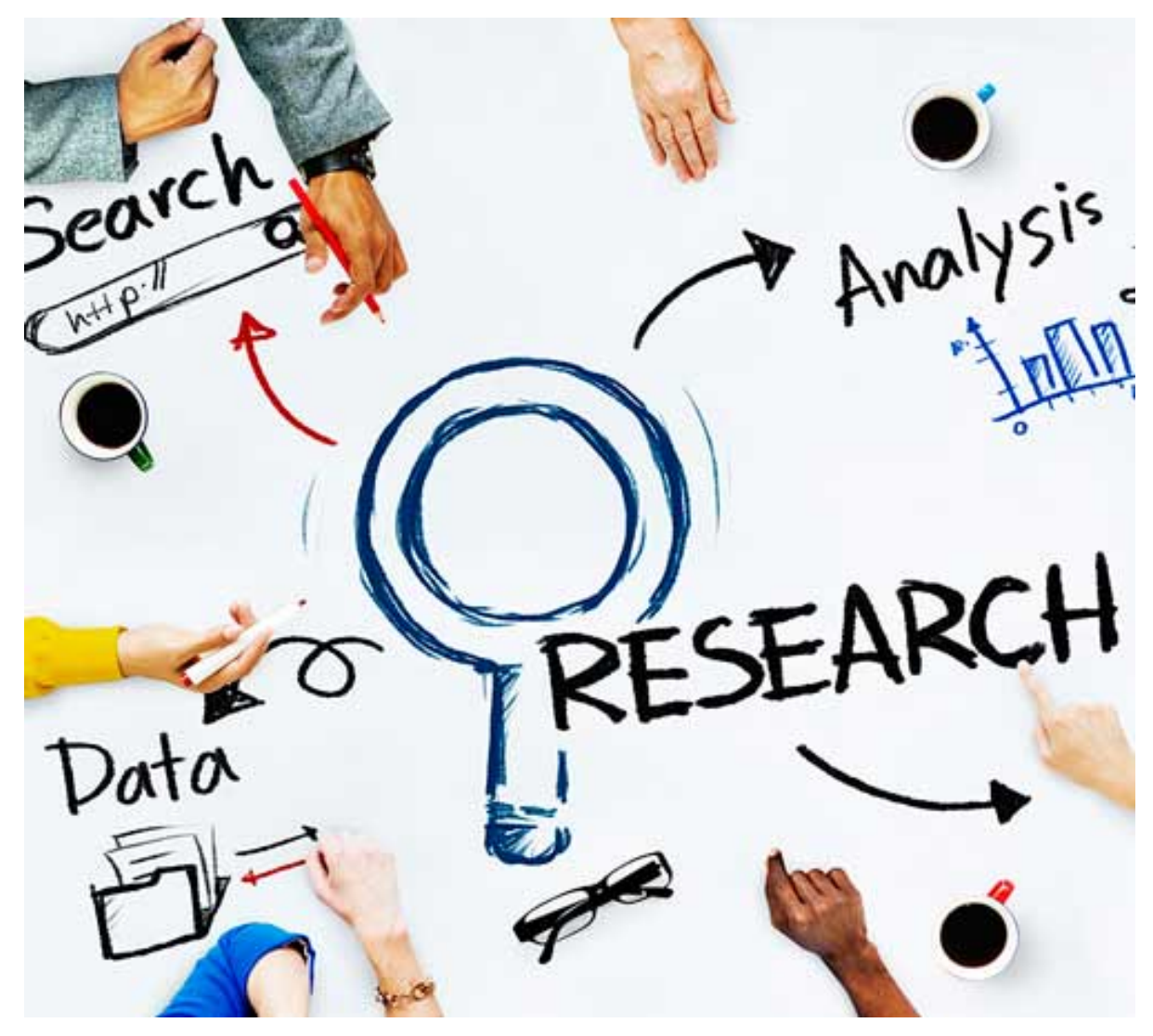


Methodology Handbook: Ethnography and Data Analysis

TRANSGANG Working Papers 4.1

NS: TRANSGANG_WP04.1/2020

Edition: May 11, 2020

\section{Authors}

Carles Feixa Pàmpols, José Sánchez-García, Roger Soler-i-Martí, Eduard Ballesté Isern, Nele Hansen, Adam Brisley

\section{Work distributed under CC licence}

\section{(c) (†) $\ominus$}

\section{(C) TRANSGANG \& UPF}

\section{Recommended format for citation}

Feixa, C., Sánchez-García, J., Soler-i-Martí, R., Ballesté, E., Hansen, N., Brisley A. (2020). Methodology Handbook: Ethnography and Data Analysis. Barcelona: Universitat Pompeu Fabra \& European Research Council. http://dx.doi.org/10.31009/transgang.2020.wp04.1.

ISBN: 978-84-09-20996-5

www.upf.edu/web/transgang

transgang@upf.edu

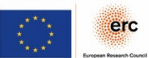

The TRANSGANG project has received funding from the European Research Council (ERC) under the European Union's HORIZON 2020 research and innovation programme under grant agreement $\mathrm{n}^{\circ} 74270$ 


\section{Table of Content}

Table of Content ................................................................................................

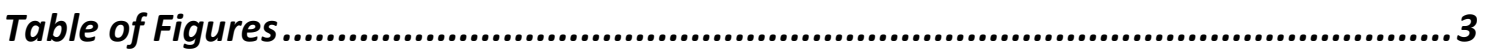

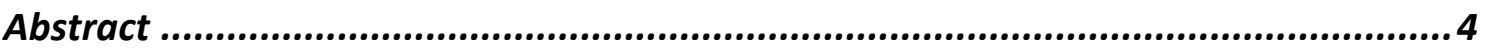

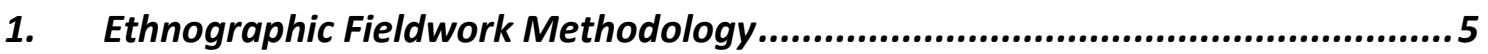

1.1. Ethnography in TRANSGANG Project ............................................................. 5

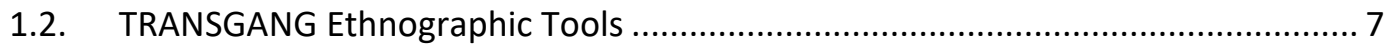

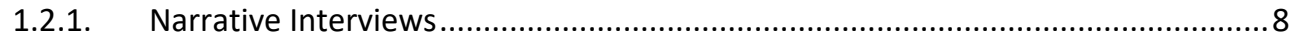

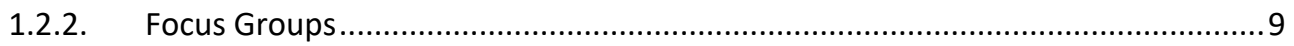

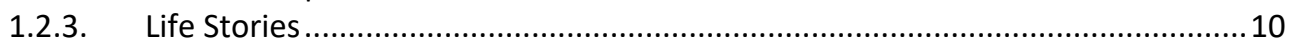

1.2.4. Participant Observation ........................................................................... 12

1.3. Meta-Ethnography as Method of Data Analyses .............................................. 13

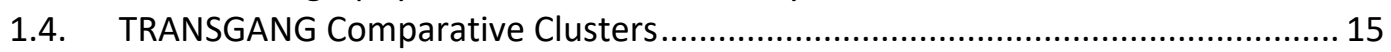

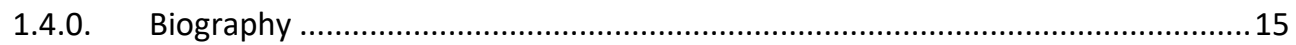

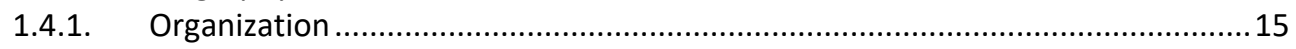

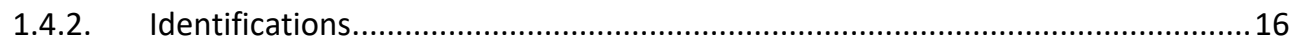

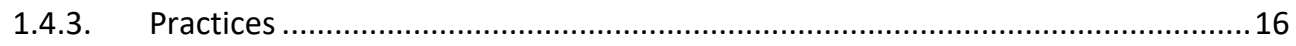

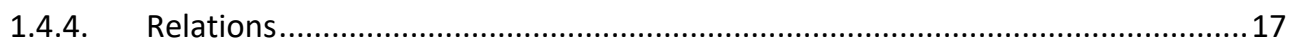

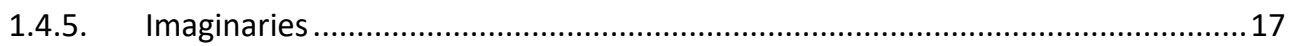

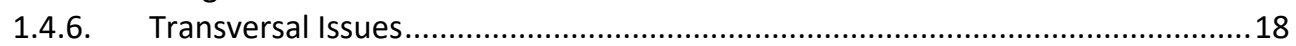

2. Strategy for Primary Data Analysis using NVivo ........................................ 19

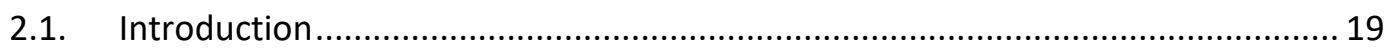

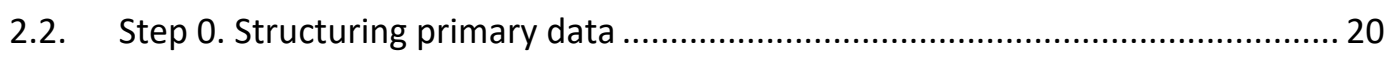

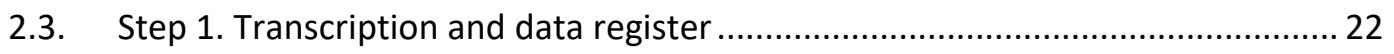

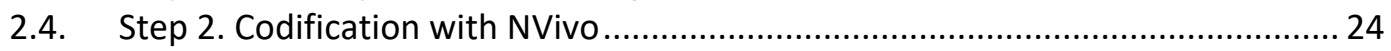

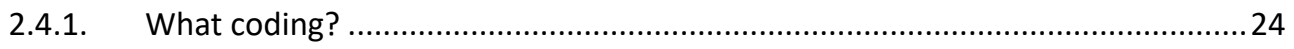

2.4.2. Enter and structure data with NVivo.............................................................24

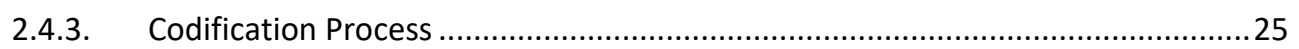

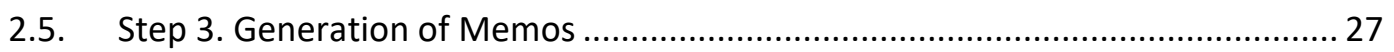

2.5.1. Interview, Life Story and Focus Group Memos ...............................................27

2.5.2. Fieldwork Diary Memos ...............................................................................28

2.5.3. Node Memos: Sharing the encoding …………………………………….......29

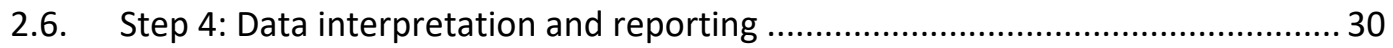

2.7. Step 5: Archiving and sharing of data, memos and reports .............................. 31

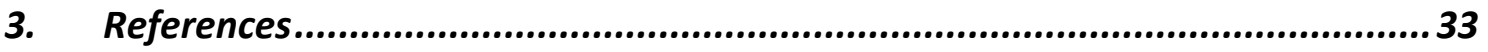

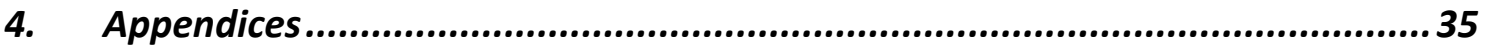

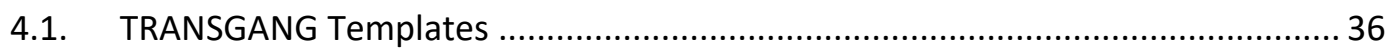

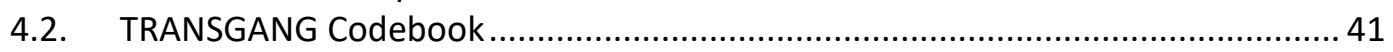

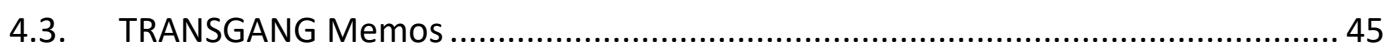

4.4. TRANSGANG Dropbox Data Location and Saving Process................................... 50

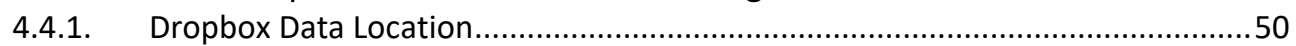

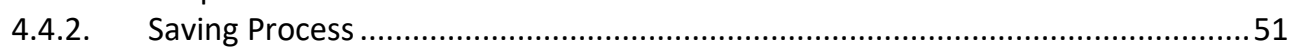

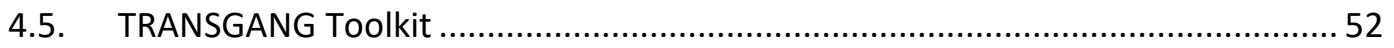




\section{Table of Figures}

Fig. 1. Youth Street Groups Micro-cosmos ..................................................... 7

Fig. 2. TRANSGANG Ethnographic Techniques, Tools and Reports .........................8

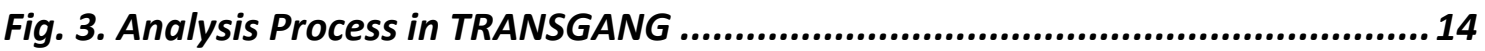

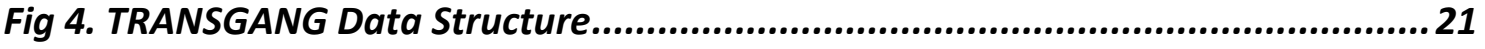

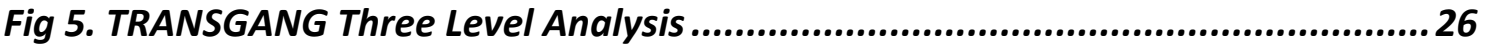




\section{Abstract}

This document is sharing the methodological perspective on ethnography and data analysis of the TRANSGANG project. The aim is to provide to the local research teams a guide about ethnographic perspectives, tools and data analyses strategy, to be able to apply using NVivo software, and some references to ensure these perspectives.

The objective of the TRANSGANG project is a comparative investigation based on one stage of local analysis and two stages of secondary analysis of the data collected according to the methodological approach. These three-level analyses will combine the results in a unique and transnational picture of street youth groups without losing the cultural particularities of the different places. The central and contrast cases involve a combination of qualitative techniques (our tools) such as narrative interviews, focus groups, life stories and participant observation, but it is necessary to work with similar analysis categories in each country.

This document has three main parts. In the first part, it provides a discussion about ethnography as research strategy, their limitation and implications and the view of ethnography as methodology in TRANSGANG project; a short description of the techniques to improve in the local contexts; a discussion and arguments to use metaethnographic analyses and, finally, the presentation of the TRANSGANG clusters discussed in the Barcelona kick off meeting with some additions.

The second part presents the systematization strategy for the treatment, coding and analysis of the primary data of the TRANSGANG project. It is a guide to share the guidelines in the treatment of the data from the interviews, life stories, discussion groups and field diaries of all the cities of the project and for all the local research teams. The objective, to get the most out of the enormous fieldwork, is to propose from the beginning a shared strategy for structuring, processing, storing and coding the primary data. In this way, the analysis phase will be able to have a direct and systematized source of the primary data that emerged during the field work.

The third part includes four Appendix that contain the basic tools and templates for the concrete application of the ethnographic and data analysis strategy: a) The memos templates for data analysis; b) The codebook with the main categories for data analysis using Nvivo; c) The toolkit with a link to all the documents and templates necessary for conducting fieldwork; and d) The organization of the dropbox folders for uploading the anonymized documents. 


\section{1. \\ Ethnographic Fieldwork Methodology}

\subsection{Ethnography in TRANSGANG Project}

Traditionally, ethnography has been the main method of obtaining qualitative comprehensions of how others worlds are experienced. Our research team will share the youth street groups' worlds across three continents to obtain the verstehen and, at same time, primary data for the comparison between street youth organizations and sociability of two transnational communities - Latinos and Maghrebi- both in their countries of origin and in diasporic situations. The project has established three locations as core cases: Barcelona, Medellin and Casablanca with three case studies in each of them. By his side, contrast cases about youth groups in Madrid, Marseille and Milan in southern Europe; Tunisia, Alger and Djendel (Algeria) in North Africa; Chicago, Santiago de Cuba and San Salvador in the Americas are been 'ethnographed'.

Our standpoint combines post-subcultural studies and decolonial theoretical perspectives with critical criminology focusing on challenging traditional understandings and uncovering false beliefs about youth street groups (see Concept Paper). As a result, the combination of these viewpoints facilitates look at the field within the social structure of class and status inequalities and considers law and punishment of crime as connected to a system of social inequality and as the means of producing and perpetuating this inequality.

In this perspective, ethnography is necessarily an open and dialogic mode of social investigation, and thus resists easy codification. The purpose of this note is therefore not to provide prescribed ways of working, nor to define the detail of how individual ethnographic studies should be undertaken. Rather, the intention is to create an agreed framework and understanding within which the ethnographic case studies can be conducted. Karen O'Reilly gives a 'minimal definition' of ethnography as:

\footnotetext{
...iterative-inductive research (that evolves in design through the study): drawing on a family of methods; involving direct and sustained contact with human agents, within the context of their daily lives (and cultures); watching what happens; listening to what is said; asking questions; and producing a richly written account that respects the irreducibility of human experience; that acknowledges the role of theory, as well as the researcher's own role; and that views humans as part object/part subject. (O'Reilly, 2005, p. 2)
}

What is more, this style of ethnographic practice allows us to provide multiple forms of data, a dialogical relationship between researcher and the researched, and to produce knowledge that potentially contributes to social reform; emphasizing the creative and agency capacity of the members of youth street groups, their cultural productions and 
their forms of sociability as resistance practices, contradictory and ambiguous at same time, against a set of discrimination processes in relation to culture, class, gender and ethnicity. On the one hand, these groupings are seen as places of production and social transformation, on the other hand, the reproduction dynamics are also evident, that is, the homologies between their functioning logics and their symbolisms (masculinity, strength, authority, hierarchy) and the global functioning of society.

According to comparative aim and transnational perspective it is necessary to go beyond a top-down approach, and move towards definition and learning from solid comparisons located within a broader structural context. Rather than start with deductive reasoning, for example, the "comparative sociology of urban marginality" of Wacquant (2008), between Chicago and Paris, seeks to inductively compare geographically distant locations. For him, the first-hand observation is an indispensable tool, first to pierce the screen of the discourses that revolve around these territories of urban perdition [...] and, secondly, to capture the lived relationships and the meanings that constitute the daily reality of the marginal city dweller (Wacquant, 2008, p.9).

This form of comparative ethnography, however, is exceptionally rare. Long-term involvement in diverse social environments requires a bilingual cultural sensitivity and an academic commitment that is as demanding as it is prolonged. The collaborative ethnographic methodology of Burawoy $(1998,2009)$ offer an alternative that is based on the efforts to understand the global "forces, connections and imaginations" in which, through deep observation, social realities can be perceived that are increasingly interconnected, although disparate. Such an approach can be found in Burawoy's (1998, 2009) Extended Case Method (hereinafter, ECM).

Moreover, an ECM approach includes a commitment to multisite ethnography (Marcus, 1995) and relational ethnography (Desmond, 2010). In multisite ethnography, the research is carried out in multiple geographic and virtual areas as the actors follow through the multitude of sites in which they act. The mediators of these activities are also a focal point: material artefacts such as documentation, more abstract structures such as rules and regulations, and acceptable and legitimated behaviours and practices. Above all, it is worth maintaining a file of juvenile artefacts from the daily life of the research participants: fanzines, writings, photos, videos, blogs and other communication materials.

By other side, relational ethnography is an alternative group and place-based fieldwork useful in multisite ethnographies, taking as its scientific object neither a bounded group defined by members' shared social attributes nor a location delimited by the boundaries of a particular neighbourhood or the walls of an organization but rather processes involving configurations of relations among different agents or institutions. In our case, according with the comparative aim, more than studying gangs, we are interpreting processes with blurred boundaries in different locations with very different social, political and economic conditions. So, more than construct 'subjects' of research in an inductive manner, the objective of the ethnographers is to follow configurations of relations. The focus of fieldwork becomes to describe a system of relations, "to show 
how things hang together in a web of mutual influence or support or interdependence or what have you, to describe the connections between the specifics the ethnographer knows by virtue of being there" (Becker 1996, p. 56).

Thus, more than to construct "subjects", "youth street groups" or "gangs" in an inductive or deductive manner, the objective of the ethnographers is to follow configurations of relations. Methodology construct the pitch, in our case "youth street groups micro-cosmos" encompassing those agents that are part of it (state, academia, media, the gang, themselves among others) to understand how this field works what positions each of these agents occupies (although positions are variable and see what dynamics are generated.

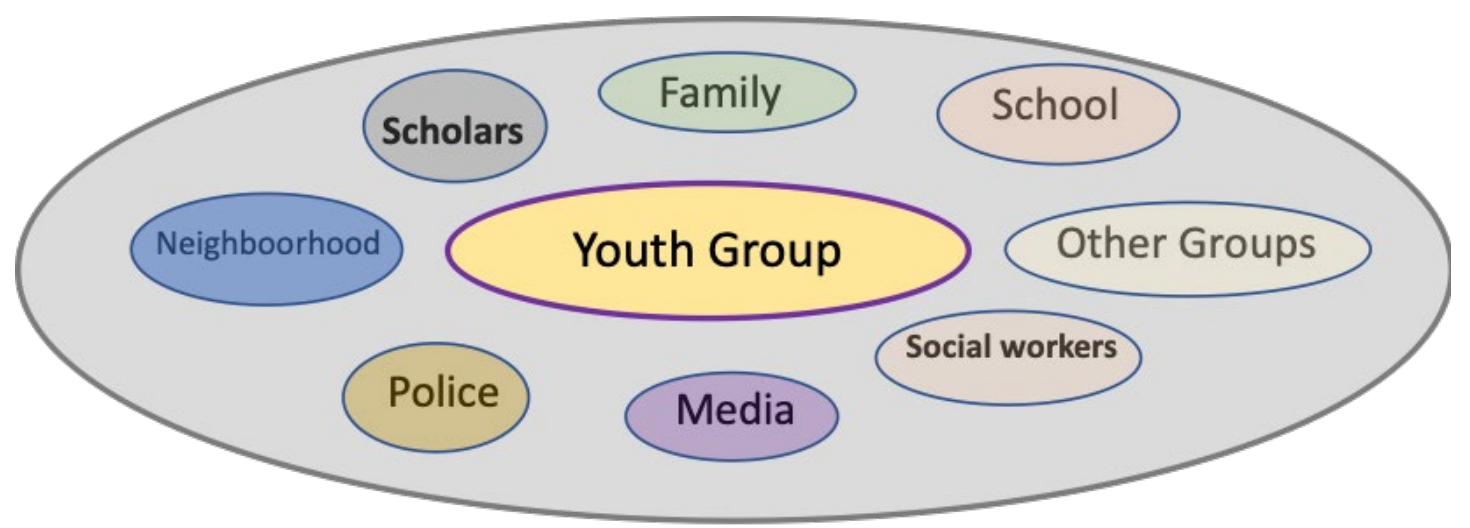

Fig. 1. Youth Street Groups Micro-cosmos

It does not seek to understand if a certain group or community is peculiar vis-à-vis their counterparts in other contexts. Most basically, a relational approach incorporates fully into the ethnographic sample at least two types of agencies occupying different positions within the social space and bound together in a relationship of mutual dependence or struggle.

\subsection{TRANSGANG Ethnographic Tools}

Every researcher has designed a research plan in the fieldwork locations related to TRANSGANG objectives. The case studies, both contrast and core, should be representative of all TRANSGANG research dimensions. Case studies may be unique in terms of their geographical location, substance or nature of the youth street groups involved, therefore. However, the transnational nature of the project and analysis to be conducted requires that case studies fall into the 'clusters' (see section four).

As noted above, we anticipate data collection to compose a final ethnographic report that will involve a combination of ethnographic fieldwork reports following our templates guide (Narrative Interviews, Focus Groups, Life Stories and Participant Observations Template) in each city. Focus groups, at same time, a research type and a technique could determine the representation and self-representation, and values of 
young people in the five countries. This is related to the conceptual objective of the TRANSGANG project. Meanwhile, life stories (constructed implementing the techniques of narrative interview) could help to clarify everyday life conditions, aspirations and trajectories of young people involved in youth street groups:

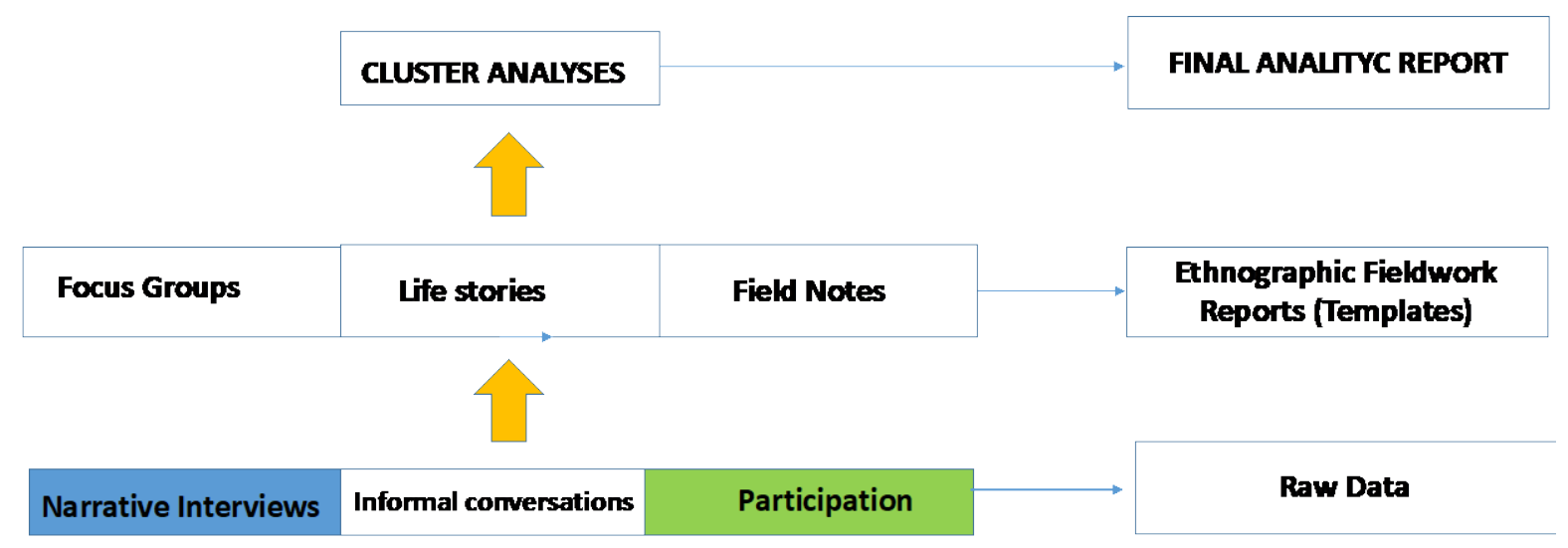

The exact balance between the uses of these different tools will depend on the nature of each case. In some cases, it may be difficult to access respondents for interviews but participation in meetings, demonstrations, 'happenings' may generate extensive field notes and visual and textual materials. In such cases, we would not expect researchers to pursue interviewees until they get the full number (regardless of quality or centrality of the interviewees to the group etc.). In such cases, informal conversations recorded in field diaries, for example, may well generate as valuable material as a more formal interview. In general, however, material from recorded interviews forms the bedrock of ethnographic investigation and these should be undertaken wherever possible.

\subsubsection{Narrative Interviews}

Narrative interview (NI) is a non-standardised interview technique used in qualitative research (for an overview see Bauer, 1996 and Flick, 2009). In this paper, we refer to this technique as defined and described by the German sociologist Fritz Schütze, since the 1970s (Schütze 1977; 1983 - in German; Schütze 1984/2005, in English).

The objective of NI is the reconstruction of the interviewee's experience, according to his/her subjective system of values. The interviewee builds a story, a narrative, of her/his experience; these stories reconstruct the time and space of the interviewee's everyday life, his/her orientations and his/her projects and strategies.

The NI reveals aspects particularly relevant when it comes to the relationship between the individual experience and the social world. The transcription of NIs uncovers the social structures that frame interviewees' experiences at a macro level. This is possible thanks to the formal character of the narrative generated by the NI. In fact, the internal 
logic of the narrative -which compels the narrator to detail his/her story while respecting the rules of any narrative, which we will discuss later in this paper- highlights the general circumstances that have framed the experience, and links single parts of the story being told to the whole narrative. The narrative scheme is indeed an elementary institution of the human communication; as such, it is governed by specific rules. Recounting one's own experience is thus subjected to a number of obligations such as, for instance, commitment to narrate the details of past experiences, to conclude the story and to "condense", or summarise, the recounted experience.

In short, the specificity of this interview technique is linked to the characteristics of the narration as a fundamental and social mean of communication with specific traits. Its effectiveness is based on the interviewee's ability to narrate -an activity usually practiced in daily life, albeit under distinct circumstances- which is here inserted in a different frame. While NIs reveal much of the interviewee's social background, values orientations and past experience; besides that, the rules that govern narration allow a great degree of control over the interviewee's narrative choices comparing to a usual open interview.

Narrative interview technique has a wide range of applications; among them, the following areas can be mentioned:

1. Analysis of interactive fields. Different narratives of the same events are compared, through interviews to different protagonists (in different positions).

2. Analysis of changed or changing social or biographical status. Different experiences of the same biographical articulation and turning points are compared, for instance: formative stages, professional career stages, or marginal moral career (alcoholics, drug addicts, homeless...).

3. Analysis of biographical structures: different experiences of common or similar biographical moments are compared, in order to understand the general characteristics of these biographical structures.

The third area of application is the most relevant for the qualitative fieldwork in TRANSGANG project.

\subsubsection{Focus Groups}

The focus groups have become an important research tool for social scientists applied by those working in program evaluation, public policy, advertising and communications. There are many definitions of a focus group in the literature, but features like organised discussion (Kitzinger, 1994), collective activity (Powell et al., 1996), social events (Goss \& Leinbach, 1996) and interaction (Kitzinger, 1995) identify the contribution that focus groups make to social research. Powell et al define a focus group as "a group of individuals selected and assembled by researchers to discuss and comment on, from personal experience, the topic that is the subject of the research" (1996, p. 499). Hence, the key characteristic that distinguishes focus groups is the insight and data produced by the interaction between participants. Posts to be clarified, the focus or discussion groups is usually considered as 'a specific technique within the 
wider group interviews aimed at obtaining qualitative information (Morgan, 1988, p. 12). It could be included the nominal group technique, the Delphi technique, 'brainstorming' and leaderless discussion groups" (Vallés, 1997, p. 287-289).

The technique of focus groups or discussion occupies a place somewhere between the two main ways of obtaining qualitative information in the social sciences: individual interview techniques and observational participation techniques. As a form of qualitative research, focus groups are group interviews, although not in the sense of an alternation between the researcher's questions and answers of the research participants. Instead, there is a dependence of the interaction within the group, based on the themes provided by the researcher, who typically takes the role of moderator. Fundamental data produced by focus groups are transcripts of group discussions. In the social sciences, focus groups allow interviewers to study people's perceptions and self-perceptions in a more natural conversation pattern than typically occurs in a one-to-one interview. They can be used for learning about youth street groups' main issues, conflicts and perceptions.

A first definition of the focus group leads to its manifest aspects: meeting people, between six and ten, previously unknown to each other, talk about a topic under the direction of another person. It is as if the survey research, the technique of most popular social research, it was defined as the individualized collection of questions, established in a questionnaire by an interviewer. In short, the focus group is constructing a situation, which aims to provoke a symbolic behaviour, be it dialogue, discussion, talk. As dialogue, building a "content" from building a "relationship". It starts from the assumption that the dialogue is the difference between "content" and "relationship. ${ }^{1}$

\subsubsection{Life Stories}

The life story is one of the older techniques used in social sciences for collecting personal and social data. It consists in a narrative of an individual about his/her personal experiences across time, normally based on successive oral interviews between the interviewer (a researcher) and the interviewee (a member of the social group under investigation). The autobiographical imagination is the creative cooperation between a subject and a researcher, who are engaged in the construction of a writing on subjectivity (Feixa, 2018). Even if the form can be literary, the content is cognoscitive: reading a social history through a life story (Ferrarotti, 1980). Here some definitions:

Story that realizes the experience of a person who exposes his activities as a human being and as a participant in social life. (Blumer, 1939, p. 29; in Scepanski, 1978, p. 238).

The autobiography is a document of personal, conscious of the author, expressing their Subjective experiences, as not all human statements are intended to have a scientific activity. His great direct value as a document of life is based on revealing a number of experiences of various kinds, but interrelated and represent a whole. (Chalasinski, 1938; in Scepanski, 1978, p. 238).

\footnotetext{
${ }^{1}$ For further discussion see

https://www.researchgate.net/publication/321222181_Focus_Groups_Issues and Approaches
} 
We understand the life history autobiography, obtained by the researcher through successive interviews, in which the aim is to show the subjective testimony of a person in which both events are collected as assessments that person makes his own existence. (Pujadas, 1992, p. 48)

The life story should be distinguished from the life history. While the second refers to an objective trajectory of an individual in a particular space and time, expressed in verifiable facts and events, the first refers to the subjective elaboration of this trajectory, expressed though an interpersonal dialogue, a personal narrative that includes selfconsciousness and reflexivity. From this point of view, a narrative interview becomes a life story when accomplish five criteria:

1. Interaction: must be the result of the interaction between researcher and informant

2. Globality: should give an overview of a biographical history

3. Orality: should reflect the transition from orality to writing

4. Multidimensionality: should collect objective and subjective aspects (values and practices)

5. Advertising: must have spread in public areas (academic, community, social).

Summarizing, the life story is a first-person account of the personal and social experiences that have marked the biographical trajectory of a subject. In this case, it is about collecting the story of people who have been part of or continue to be part of youth gangs, and who have been involved in mediation and conflict resolution processes. By definition, the life story is a free story, which must be adapted to the idiosyncrasy of each subject, both in the way of telling his life (the language), and in the content of that story (the aspects, dimensions, stages significant) and in the way of ordering such memories.

In principle, the TRANSGANG life stories will be the result of a minimum of three interview sessions. The first one may coincide with the in-depth interview (see Template). The second will consist of a completely free story about the trajectory of the subject. The third will be a guided interview, based on the attached script, trying to fill in the gaps of the first two interviews (it should not be followed at face value but as an orientation). If the testimony allows it, successive interviews can be made with the informant or with members of their environment (relatives, friends, gang members, etc.). In some cases, you can also join the first and second interviews in a single session.

Each session will last between one and two hours (in total a minimum of 3 hours of interview). Complete transcription will be required, following the criteria of informed consent, anonymity and protection of data and project sites. Subsequently, a narrative version of the life story will be elaborated, starting from the literal transcription, eliminating the interviewer's questions and rearranging the content from the script structure, but without adding anything new, but in order to make it readable and understandable. 


\subsubsection{Participant Observation}

As it is noted by Schütz, "the buildings used by the social scientist are, therefore, so to speak, constructs of the second degree, namely constructs of the constructs made by the actors in society itself, actors whose behaviour the researcher observes and tries to explain according to the procedural rules of his science" (Schütz, 1974a, p. 37-38). Any ethnographic research focuses is a youth street groups realities in both core and contrast cases considering their internal diversities. It supposes a grade of considerable complexity, since your connection is not merely unique; there is a continuous 'slippage' of concepts built in sociology, in which appropriate them individuals for analysing whose conduct were originally coined, and therefore tend to become integral features of this behaviour. This epistemological perspective facilitates the understanding of human behaviour from the reference frame itself who acts. This knowledge is rooted in phenomenologism and verstehen (understanding), hermeneutic/understanding, and can be located at a number of different levels. First, the intuitive level, understanding intuitively grasp the inherent capacity personal meanings to a social context. Secondly, the knowledge through experience. And finally, the knowledge through personal, empathic or sympathetic identification.

In consequence, for the ethnographer is necessary to apply the so-called participant observation as general strategy in their investigation. This technique is one type of data collection method. Its aim is to gain a close and intimate familiarity with a given group of individuals and their practices through an intensive involvement with people in their cultural environment. This qualitative method has their roots in traditional ethnographic research, whose objective is to help researchers learn the perspectives held by study populations. Qualitative researchers accomplish this through observation alone or by both observing and participating, to varying degrees, in the study community's daily activities.

The method is distinctive because the researcher approaches participants in their own environment rather than having the participants come to the researcher. Hammersley and Atkinson (1994) distinguish seven main stages of participant observation: (1) initial contact; (2) shock; (3) discovering the obvious; (4) the break; (5) focusing; (6) exhaustion, the second break, and frantic activity; (7) leaving. The researcher engaged in participant observation tries to learn what life is like for the members of the group while remaining, inevitably, an "outsider." While in these community settings, researchers make careful, objective notes about what they see, recording all accounts and observations as field notes in a field notebook. Informal conversation and interaction with members of the study population are also important components of the method and will be recorded in the field notes, in as much detail as possible. Information and messages communicated through mass media such as radio or television may also be pertinent and thus desirable to document. ${ }^{2}$

A central question for any investigation relates to the degree of confidence in the "truth" that the findings of a particular inquiry have for the subjects with which -and the context

\footnotetext{
${ }^{2}$ For more details see: http://www.qualitative-research.net/index.php/fqs/article/view/466/996.
} 
within which- the inquiry was carried out. Within the prevailing research paradigm truth value is described in terms of internal validity, that is, the isomorphic relationship between the data of an inquiry and the phenomena those data represent. However, more pertinent is the compatibility of the constructed realities that exist in the minds of the inquiry's respondents with those that are attributed to them. This relationship is termed credibility and needs to be established with the individuals and groups who have supplied data for the inquiry. It is assessed by determining whether the description developed through inquiry in a particular setting "rings true" for those persons who are members of that setting. Because these persons represent different constructed realities, a credible outcome is one that adequately represents both the areas in which these realities converge and the points on which they diverge. A credible inquiry generally has the effect on its readers of a mosaic image, often imprecise in terms of defining boundaries and specific relationships but very rich in providing depth of meaning and richness of understanding.

Lastly, two strategies are suggested here to facilitate transferability of participant observation. Initially, thick description (Geertz) because transferability in a naturalistic study depends on similarities between sending and receiving contexts, the researcher collects sufficiently detailed descriptions of data in context and reports them with sufficient detail and precision to allow judgments about transferability. Effective thick description brings the reader vicariously into the context being described. And secondly, purposive sampling because the foundation of transferability is an adequate description of the sending context, the search for data must be guided by processes that will provide rich detail about it. In contrast to the random sampling that is usually done in a traditional study to gain a representative picture through aggregated qualities, naturalistic research seeks to maximize the range of specific information that can be obtained from and about that context. This requires a sampling procedure that is governed by emerging insights about what is relevant to the study and purposively seeks both the typical and the divergent data that these insights suggest.

\subsection{Meta-Ethnography as Method of Data Analyses}

Meta-ethnography is a method for the synthesis of qualitative empirical data that is interpretive rather than aggregative in approach; it works through the principle of the 'reciprocal translation' of the meanings of one case into the meanings of another. When we use the term 'synthesis' in the specific TRANSGANG context, we are referring to the process of synthesising data from local researchers in order to generate 'themes' (meta-codes/metaphors) that work at a trans-case (transnational/regional) level. This synthesis does not replace local level analysis; it provides one additional layer of analysis that can be presented as the value-added of conducting multiple case studies in a large number of national and local contexts.

After the translation of the conceptual approach of TRANSGANG on youth street groups to local conditions, every ethnographic fieldwork researcher or team will report 
their case study based on narrative interviews, focus groups, observant participation and life stories and using NVivo software. In the next stage, the ethnographic area coordinator will develop an interpretation of the interpretation considering the objectives of the project and a synthesis of every researcher results. This is the second interpretation in accord with all ethnographers. The third stage is an interpretation of the interpretation of the interpretation that it will be carried out by UPF team with the support of local researchers.

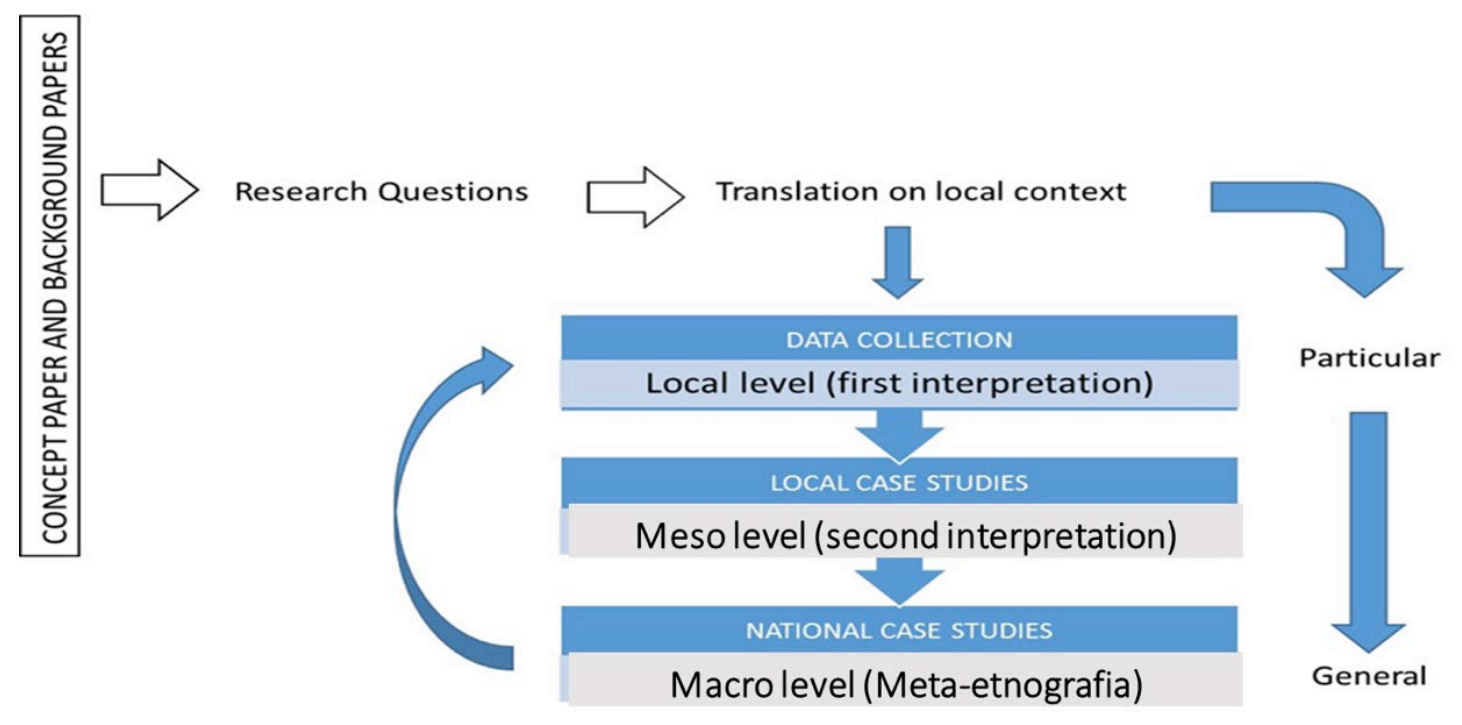

Fig. 3. Analysis Process in TRANSGANG

Analysis always involves the organisation of propositions which already include an interpretation, a representation of the forms of social reality. It is the question of whether a particular strategy for analysis of qualitative data is likely to generate a theory. In our case, this strategy should let emerge 'grounded theory'. In this sense, the idea of an "analytic induction" employed by Znaniecki (1972) among others could be useful. This analytical strategy tries to abstract from local contexts the main patterns of the investigated processes to find local variables and, then, elaborate models. It tries to harmonize all the partial models with each other. This strategy combines systematic coding and evidence mapping with more creative analysis of information. In the case of TRANSGANG this strategy will allow, precisely, the implementation of our metaethnographic objectives without losing local particularities.

Here we will use the tool of "clustering", considering the first and second interpretation. Clustering means to find common themes across the local case studies. The clusters (representing analytical categories also), drawn from the topics and main research questions of TRANSGANG (and proposed by UPF to be discussed and confirmed in the Kick off meeting in Barcelona) gives the chance to compare the datasets from each case (contrast and core) with different topics and issues, related to the everyday life of street groups. In other words, the clusters are the measuring sticks, to make the diverse 
case studies comparable. The last interpretation will check by researchers to ensure that every member of TRANSGANG ethnographic team will be agree with this last interpretation on a transnational level.

\subsection{TRANSGANG Comparative Clusters}

The Ethnographic fieldwork is the main pillar of the TRANSGANG Project and consists in producing qualitative data related to the objectives of the project to allow for the writing of many upcoming deliverables (scientific papers, policy papers, etc.). In the data analysis we will use clustering to implement all levels of interpretation. As we said before, clustering means finding common themes in the local case studies. Based on the discussions produced in the Barcelona Kick Off meeting, and several discussions with local researchers and teams, the TRANSGANG UPF team has produced seven clusters with different themes/topics, in which the cases (composed by focus groups, narrative interviews, life stories and participant observation notes) from the 12 cities can be embedded. The use of these seven different dimensions in the research is forced but it is necessary for heuristic reasons. In social reality, all of these variables appear imbricated and juxtaposed and some data will be included in more than one dimension. Moreover, the research questions presented here were agreed during the theoretical and methodological discussions celebrated in Barcelona's Kick off meeting in September 2018. The research questions are only examples to consider it for the final report. According to our theoretical perspective, TRANSGANG has adopted seven thematic dimensions and some research question for each:

\subsubsection{Biography}

A special dimension has been established for biographical questions that it can be interesting to understand the analyses and very helpful to produce life stories. This dimension will classify the specific biographical information not present in other clusters, in particular those that define the family and social background and the moments of change in the life course.

Questions:

- The fact of being a youth street group member is an advantage or a disadvantage for getting a job?

- What leads young people to join? Which are the aspirations of a member to join a group?

- What sense does it make in their lives to be a group member? How does the group help forge a meaning in their lives?

\subsubsection{Organization}

This dimension describes the internal forms of organization of the group that support its structure and functions, the result of its history if the group has it. Also includes their 
structure and agency, procedures for entry, membership and exit of the group. The origins of the group and evolution up to the present; vertical structures (hierarchy) and horizontal structures (brotherhood) that bring the group together. The formal and informal group activities, with some regularity and the formal or informal ways of incorporation to the group and phases through which it passes.

Questions:

- Which are the mechanisms and processes of affiliation and disaffiliation in a youth street group?

- How did these groups become global (influence of globalisation and the Internet)?

- How has the past permeated the creation and evolution of youth street groups according to the context?

- How is the horizontal and vertical relationships structure within the group?

- How is the process of decision making in the group?

\subsubsection{Identifications}

This dimension categorises collective current trends youth street groups. Moreover, the forms of subjective identification of the individual in relation to the group and the community; identity elements that convey the feeling of belonging to the group. If the focus is on individual, and personal identity, it is understood as: 1) chosen: "I am who I say I am"; 2) bestowed: "I am who others say I am"; 3) simultaneous: "I am more than one identity at the same time"; 4) strategic: "I am who I am depending on the circumstances"; and 5) virtual: "I am who I am shaped by global telecommunications". This dimension will be analysed through topics such as members (socio-economic profiles, ethnic, age and gender), spaces/territories, expressive symbols, aesthetics (dress, body uses...), leadership, rules, organization, media presence and leisure).

Questions:

- How do individuals negotiate their role and identity within the group?

- How is group identity constructed in contrast with other social formations?

- How are the symbols of a group transformed/transferred among members of different generations? What is the meaning of symbols in groups?

- Does the group determine how do members have to behave outside the gang?

- The fact of being a member is an advantage or a disadvantage for getting a job?

\subsubsection{Practices}

This dimension identifies, describes and analyses the different cultural practices of youth street groups in relation to the articulation of different social intersectional conditions (age, class and ethnicity) in specific contexts. We include the ordinary and extraordinary activities of the members of the youth street groups; the experiences of formal, no formal and informal education at individual level and also at a group level (transmission of the group values); experiences of formal and informal work; legal, not 
legal but legitimate and illegal ways of earning money. Also the use of the leisure time, commercial and not commercial, online and offline, including the experience of "doing nothing"; the violence exercised or suffered and the experiences of participation in prosocial activities, in defence of the group or the community.

\section{Questions}

- Which activities does the group do in order to access different resources?

- Which are the daily and intersectional practices of the group and their members?

- What kind of practices have they got? And which public spaces do they use?

- How is the coexistence of members in public spaces with other social agents? What are the uses and practices represented in the media?

- How does the group mobilize social resources in situations of crisis and need?

\subsubsection{Relations}

This dimension makes it possible to analyse the institutional and virtual relations of youth street groups with other individuals, groups, neighbourhoods and social institutions (school, family, police, prison...). Moreover, it is significant to analyse the social relations of members of street youth groups, both internal and external (with other groups, with adults, with the state and with society civil).

Questions:

- How does the group relate with adult generations?

- How does the group relate with the State/Administration?

- How does the group relate with other youth street groups?

- How is the relationship with other social groups? And with civil society?

- How are the relationships with relatives and other members' families?

\subsubsection{Imaginaries}

This dimension identifies, describe and analyse the symbolic elements that convey the personal and group identity of the members of street youth groups and symbolic elements that convey the identity of the street youth groups; and their myths and legends. Also, the values of the street youth groups: oral or written, declared or hidden is in the focus of this dimension. The religious beliefs and/or spiritual feelings of the members of groups, at individual and group level, including syncretic beliefs, practices and the participation in rituals. Finally, the vision of the future at personal, group and community levels should be included in the cluster.

Questions:

- How do other social groups see and perceive youth street groups? Are representations also reproduced across time and generations?

- What are the values of the group? How are the values represented? How is the gang's image represented through the body? Which is the role of a group's belief system? 
- Which are the aspirations of a member to join a gang? What sense does it make in their lives to be a member?

- How does the group help forge a meaning in their lives?

\subsubsection{Transversal Issues}

In this dimension all the crosscutting issues as gender, transnationality, definitions of Gang and Street Groups, experiences of formal and informal mediation, conflict resolution, truces and the impact of confinement caused by Covid-19 in everyday life will be categorized.

\section{Questions:}

- What is the presence and image of youth street groups in the media? What kind of uses and practices represented? What is the self-representation generated by the members in the media?

- How did these groups become global (influence of globalisation and social media)? What are the uses, presence and image of youth street groups in the social media? What is the self-representation generated by members in the social media?

- How the group manage conflictive situations? Are they involved in formal processes of mediation?

- How are the gender relations in the group? How do individuals negotiate their role and identity according to their gender within the group? How are the relationships with relatives, other members' families and neighbours, especially women?

- How does the group mobilize social resources in situations of crisis and need as Covid-19? 


\section{Strategy for Primary Data Analysis using NVivo}

\subsection{Introduction}

This second part presents the systematization strategy for the treatment, coding and analysis of the primary data of the TRANSGANG project. It is intended to present guidance on the treatment of the data arising from the interviews, life stories, focus groups and field diaries of all the cities of the project and for all the local research teams. TRANSGANG is an ambitious project in its research objectives and also in the dimension and scope of its analysis: 12 cities from three different continents and dozens of case studies will generate a huge amount of data with great potential for analysis. To get the most out of this large quantity of fieldwork, it is necessary to propose from the beginning a shared strategy for structuring, processing, storing and coding primary data. In this way, the analysis phase will have a direct and systematized source of primary data that emerged during the field work. This large TRANSGANG dataset will also remain a resource for future analysis on street youth groups and mediation.

The guide is aimed at offering a way to record, order and share the primary data of the project that makes possible the challenge of TRANSGANG's methodological proposal, included in the Concept Paper and in the first section of this document. Analysis always involves the organization of propositions that already include an interpretation, a representation of the forms of social reality. In this sense, in the case of TRANSGANG we must be aware that the process of coding and organizing the data implies an interpretation and, therefore, the linking and generation of theory. The question of how a particular strategy for qualitative data analysis generates theory is fundamental. For this reason, in a project with so many field researchers in such different contexts, it is essential to have systematized instruments that explain the interpretations of the process of coding and organizing the data.

Meta-ethnographic research is becoming more common. The challenge is to maintain the richness and attention to the uniqueness of particular contexts, but the meanings of ethnography in multi-case study research is not new. In many of these cases the metaethnographic analysis is carried out from the systematic review of the reports or ethnographic analyses of the different case studies. In the case of TRANSGANG, a more ambitious meta-ethnographic strategy was chosen. Developed by Pilkington (2018) for the analysis of primary data, this strategy requires a greater coordination and systematization of the codification process, not only as a mechanized process of information extraction but as a shared process with different researchers of generation 
of theory and discussion of meanings. And this is precisely the meaning of this Handbook.

The strategy presented below is organized according to the steps to be followed once the field work for the treatment, systematization and analysis of the data has been completed. It can therefore be read as a step-by-step guide.

\subsection{Step 0. Structuring primary data}

Step 0 comprises the work that must be conducted prior to starting to process the primary data of the project. Whilst it is not a formal stage of data analysis, it is nevertheless essential. In particular, the structure of the primary data of the project is specified, defining and delimiting the case studies that are the basic units on which all the analysis proposal is developed.

In order to systematize the primary data, it is necessary to establish and fix the structure of the origin of this data. In an ethnographic investigation, this structure cannot be completely fixed beforehand; therefore, the definitive structuring of the data must be flexible to introduce changes based on the unforeseen, difficulties and opportunities that arise during fieldwork and decisions that the researchers are taking. However, the project must establish a definitive structure on which the data obtained will be systematized, understanding that when the field researcher selects them, he is already interpreting the world of street groups from his position. Here we present the criteria for this structuring that must be established at the end of the fieldwork phase.

TRANSGANG fieldwork is carried out in 12 different locations in Southern Europe, North Africa and America. In each of these regions there are 1 core city and 3 contrast cities. The minimum fieldwork requirements for core cities are 12 interviews, 6 focus groups, 4 life stories and 480 hours of field observation. In the case of contrast cities: 6 interviews, 3 focus groups, 2 life stories, and 240 hours of field observation.

The most relevant element to establish a data structure in which treatment and analysis is ordered is the definition of the case studies. In the Nvivo software the basic unit that collects all the data (interviews, field diaries, etc.) from a case study is the files called "projects". Each project can accommodate a multitude of text entries, those produced from the four basic research techniques (interview transcripts, focus groups and life stories, field notes), but also other documents in text format (texts from social networks, official documents, etc.) and in other audiovisual formats (images, audio or videos). The project is the coding unit. In other words, all these audiovisual documents or files can share the same encoding of their content. 


\section{TRANSGANG DATA STRUCTURE}

\begin{tabular}{|c|c|c|c|}
\hline Primary data: & $\begin{array}{l}\text { Core locations ( } 3 \text { ): } \\
\text { - } 12 \text { interviews } \\
\text { - } \quad 4 \text { life stories } \\
\text { - } \quad 6 \text { focus groyp } \\
\text { - } \quad 480 \text { h field diary }\end{array}$ & $\begin{array}{l}\text { Contrast locations (8): } \\
\text { |. } \quad 6 \text { interviews } \\
\text { |- } 2 \text { life stories } \\
\text {. } 3 \text { focus groyp } \\
\text {. } 240 \text { h field diary }\end{array}$ & $\begin{array}{l}\text { Total: } \\
\text { - } \quad 84 \text { interviews } \\
\text { - } \quad 28 \text { life stories } \\
\text { - } \quad 42 \text { focus groyp } \\
\text { - } \quad 3.360 h \text { field diary }\end{array}$ \\
\hline
\end{tabular}

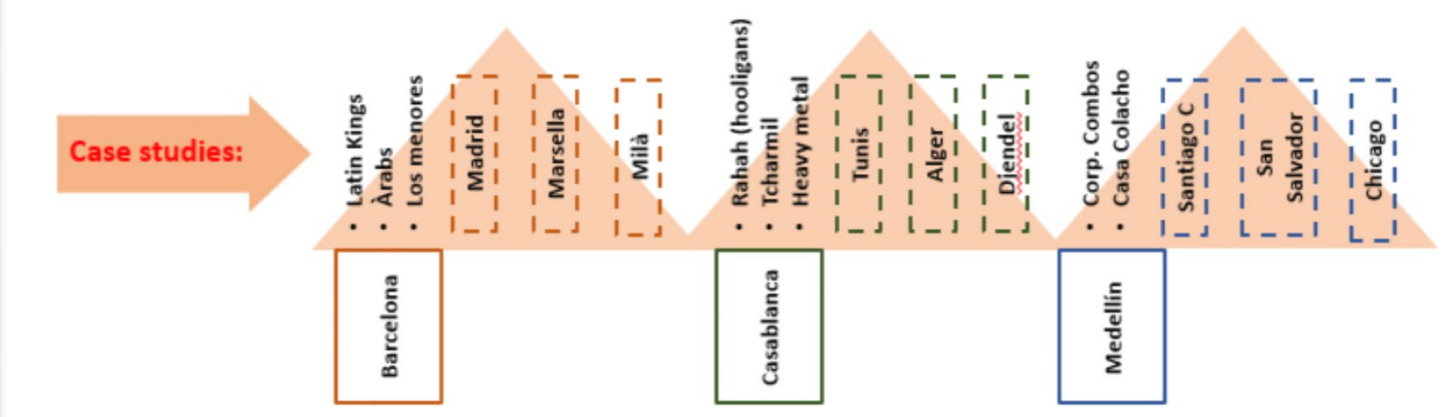

Fig 4. TRANSGANG Data Structure

In the case of TRANSGANG, a Nvivo project will be opened for each case study where all the files from the field work related to the case will be stored, encoded and analysed $^{3}$. The definition of the case studies is different depending on the type of locality:

- In each of the core cities (Barcelona, Medellín and Casablanca) different case studies are studied (in principle three in each city). Therefore, a project will be opened for each case studied. The result will therefore be 9 NVivo 3 projects for each location. These case studies can be of a different nature. Specifically they can be:

○ Gangs or street youth groups (this is the preferred and clearest type of case).

- Territories, neighborhoods or urban spaces with the presence of youth groups

- Situations or social processes in which members of street youth groups or those around them participate.

- Present or past mediation experiences with street gangs or groups.

- In contrast cities, the case study coincides with the city and, therefore, there will only be one Nvivo project. The result will therefore be another 9 Nvivo projects, one per locality.

Thus, the result will be 18 NVivo projects, corresponding to 18 case studies carried out in 12 cities in 3 different regions.

\footnotetext{
${ }^{3}$ For more practical information on how to use Nvivo please see the following manual: NVivo 12 Training Manual
} 


\begin{tabular}{|c|c|c|}
\hline \multicolumn{3}{|l|}{ CASE STUDY LIST } \\
\hline Europe & North Africa & America \\
\hline $\begin{array}{l}\text { Barcelona (core): } \\
\text { - } \quad \text { Latin Kings } \\
\text { - } \quad \text { Maghreb youth } \\
\text { - } \quad \text { Minors }\end{array}$ & $\begin{array}{ll}\text { Casablanca (core): } \\
\text { - } & \text { Rajah (hooligans) } \\
\text { - } & \text { Tcharmil } \\
\text { - } & \text { Heavy metal }\end{array}$ & $\begin{array}{ll}\text { Medellín (core): } \\
\text { - } & \text { Corp. Combos } \\
\text { - } & \text { Casa Colacho } \\
\text { - } & \text { Casa Mía }\end{array}$ \\
\hline Madrid & Tunis & Santiago de Cuba \\
\hline Marseilles & Alger & San Salvador \\
\hline Milan & Djendel (Algeria) & Chicago \\
\hline
\end{tabular}

These cases have been selected through a process of dialogue between local researchers and the project coordination team. During fieldwork, new cases may appear or the boundaries of each of these cases may expand or contract. The important thing for structuring the analysis of the data through NVivo is that once the field work is completed, the case studies are defined and the materials are distributed with primary data from the field work (transcripts, graphic material, journals of field, etc.) in said case studies.

\subsection{Step 1. Transcription and data register}

The first step in systematic data analysis is to agree on shared ways of recording and transcribing the primary data.

Concerning the transcription process, we will use the "literal transcription". In this type of transcription, all the sounds you hear are written to the document, including unfinished repeated words, pronunciation errors, sounds (like "uh ...", "mmm ..."). In short, everything that is said in the audio. In addition, transcripts must follow the anonymization procedures determined in the TRANSGANG Ethical Handbook.

The project has developed templates for the different primary data collection instruments, which is where all the information from the fieldwork has to be stored. In the case of interviews, life stories and focus groups, each of these documents must be associated with a consent form. Therefore, the documents necessary to register the field work are the following: 


\section{TRANSGANG Templates}

Interviews:

- Consent form (Template)

- Interview Transcription and socio-demographic data (Template)

Focus group:

- Consent forms (Template)

- Focus group Transcription and socio-demographic data (Template)

Life stories:

- Consent form (Template)

- Interview Transcriptions and socio-demographic data (Template)

Field notes:

- Observation notes (Template)

- Ethnographic visits (Template)

$\Rightarrow$ The ethnographic templates can be found in Appendix 1 (TRANSGANG Templates).

In addition, local researchers can collect and store other types of materials linked to the case studies that they consider relevant. These materials may be linked to the case study only or be related to TRANSGANG's Transversal Actions (Social Media Analysis, Media Representation Analysis, Visual anthropology,) or Special Issues (Gangpedia, Documentary Film. White Paper).

\section{[STEP 1] Implications (minimal) for local research teams}

Core Cities (3): Consent forms and transcriptions of:

- 480 observation hours

- 12 interviews

- 4 life stories

- 6 focus group

Contrast Cities (8): Consent forms and transcriptions of:

- 240 observation hours

- 6 interviews

- 2 life stories

- 3 focus group 


\subsection{Step 2. Codification with NVivo}

Coding is the first step in the analysis of primary data, since it introduces a first interpretation space deeply rooted in the direct results of the field work. It is important to be aware of this interpretive role in the coding process. As has been mentioned, theory is not only something that arises as a consequence of the interpretation of the data, but it plays a fundamental role in the process of knowledge production from the first decisions in the research approach and also in the choices made regarding the treatment of the data. This, in turn, means that the treatment, systematization of the data (and, in our case, its codification) is also a process of theoretical revision and redefinition (Goldkuhl \& Cronholm, 2010). Coding is to be carried out using NVivo 12 qualitative data analysis software.

\subsubsection{What coding?}

Local teams have to code the following primary data associated with each of the case studies:

- Interviews

- Focus groups

- Life stories

- Field diaries

During the fieldwork, it is likely that data will be collected in other formats (social media entries, news, graphic and audiovisual materials, etc.). NVivo allows the encoding of this type of material in the same projects in which the textual sources are going to be encoded. Coding of these materials is not a requirement of the project, although local researchers are encouraged to do so in those cases that are considered relevant.

\subsubsection{Enter and structure data with NVivo}

As detailed in step 0 , in the TRANSGANG Project the basic unit of analysis is the case studies. For each case study, an NVivo project will be opened (* nvp) where all the documents and files to encode will be stored. Within the project, the different textual or audiovisual documents arising from the field work share the same codification.

The documents to include in each project will be the interviews, life stories, discussion groups, field diaries and other materials (photos, videos, social media entries ...) that correspond to each case study.

At the time of entering the document, each researcher must enter the information that will help us all structure the data at the time of analysis. The NVivo program allows defining attributes to the different documents included in the projects that can later be very useful to compare different groups. In the case of interviews and life stories, for 
example, we must introduce the characteristics of the interviewee collected in the sociodemographic questionnaire of the interviews. ${ }^{4}$

\subsubsection{Codification Process}

Coding will be done by local researchers. As it has been emphasized, the collection and observation of data in the field already involves a first process of interpreting the information, so it is important that the researcher who encodes knows perfectly well the context well and how to interpret explicit and implicit meanings. The best way to guarantee this is that the coding is carried out by the same researcher who carried out the interview, field diary or audiovisual record.

The project plans to organize information at three hierarchical levels. The first two are subject to coding. The upper level (level 3) corresponds to clusters, which is the name given to the large dimensions of project analysis. (see Concept Paper). However, this level is implicit at the time of coding, so it should not be entered in the Nvivo project. The encoding process in NVivo, therefore, will be done at two code levels:

- A first level (level 1 nodes) with highly descriptive codes created inductively from the text or material to be encoded and using the same language as the text (in the case of text documents).

- These first-level codes are grouped into other, more extensive and interpretive codes (level 2 nodes). For this second level, a list (or tree) of codes will be proposed, in such a way that the coding process will consist of linking the firstlevel descriptive and spontaneous codes with the second-level interpretive and preset codes. For this second level, a list of codes is proposed, in such a way that the coding process consists of linking the first-level descriptive and spontaneous codes with the second-level interpretive and preset codes. Local researchers involved in the coding are encouraged to add, in each project, new second level codes specific to those first level codes that do not have a clear correspondence with any of the proposed ones.

\footnotetext{
${ }^{4} \mathrm{We}$ propose to use the attributes included in the interview transcription templates, which include basic information such as age, gender, connection to street groups, profession of the stakeholder, etc., suitably anonymous.
} 


\section{Level 3}

Project clusters

CLUSTER

Only for interpretation

\section{Level 2}

Interpretative

Defined by UPF coord. team

In English

\section{Level 1}

Descriptive

Defined by local researchers
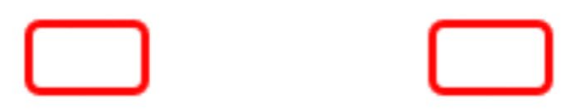

In native languages
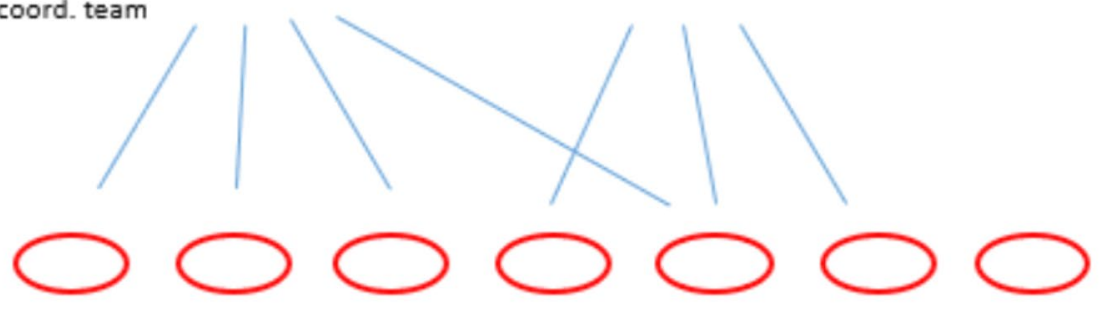

Fig 5. TRANSGANG Three Level Analysis

The second level list or codebook is proposed by the TRANSGANG coordinating team based on the analytical objectives of the project, the dimensions of the analysis, and the interview and discussion group scripts. This second level code list must be entered in all NVivo projects before the encoding begins.

The codebook contains a short description of each second level code, and some examples of first level codes that they could include. As explained in the next step, the researchers must in turn explain, for each second level code in each project / case study, what meaning and type of codes have appeared in each case study (Node Memos).

$\Rightarrow$ The list or codebook can be found in Appendix 2 (TRANSGANG Codebook).

[STEP 2] Implications for the local researcher teams

\section{Core Cities (3):}

Codification of:

- 12 interviews

- 4 life stories

- 6 focus group

- $480 \mathrm{~h}$ field diaries

- Additional Materials (optional)

\section{Contrast Cities (8):}

Codification of:

- 6 interviews

- 2 life stories 
- 3 focus group

- $\quad 240 \mathrm{~h}$ field diaries

- Additional Materials (optional)

\subsection{Step 3. Generation of Memos}

This step is aimed at minimizing the fundamental problem of proposing a comparative ethnographic investigation with such a large amount of data, in such different contexts and with different teams of researchers involved (Pilkington, 2018). The goal is to complement raw coding information with a better understanding of interpretive contexts and meanings.

At a practical level, it is intended that the primary TRANSGANG database is not only a set of citations that is systematized and ordered according to the codes that have emerged and been established, but that it also collects information about the interpretive process on which these codes have been generated (Node Memos), about the profiles and contexts in which the field work has been carried out (Interview Memos, Focus Group Memos. Life Stories Memos) and about the situations, activities, experiences and interpretations of the researcher during field work (Fieldwork Diary Memos).

$\Rightarrow$ The templates for each of these memos can be found in Appendix 3 (TRANSGANG Memos).

\subsubsection{Interview, Life Story and Focus Group Memos}

For each interview, focus group or life story, apart from the transcript, a brief report must be submitted. This report aims to help the researcher in the data analysis and interpretation phase to know the profile of the participants, their circumstances and the context in which the interview or focus group took place. It therefore must be significantly descriptive, also providing the contextual knowledge of the local researcher that allows to correctly interpret the elements and implicit meanings of the content and to understand the situations and meanings of the interview or FG relevant to the project. 

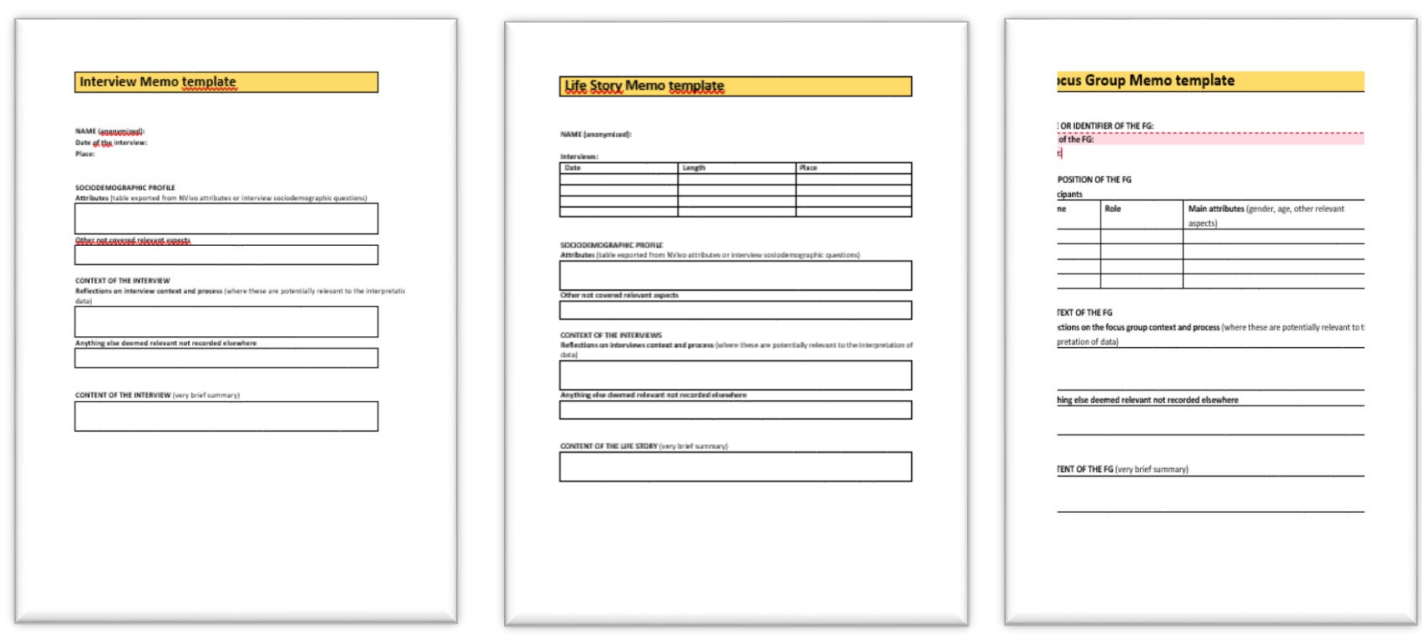

It is important that the Interview and Focus Group Memos are carried out by the researcher who has carried out the corresponding interviews, life stories or focus groups.

\subsubsection{Fieldwork Diary Memos}

These reports are essential to understand the case studies and the development of field work. A single report (Fiedwork Diary Memo) must be generated for each case study that collects all the information from the fieldwork. The primary information source for these reports are the field diaries and their coding.

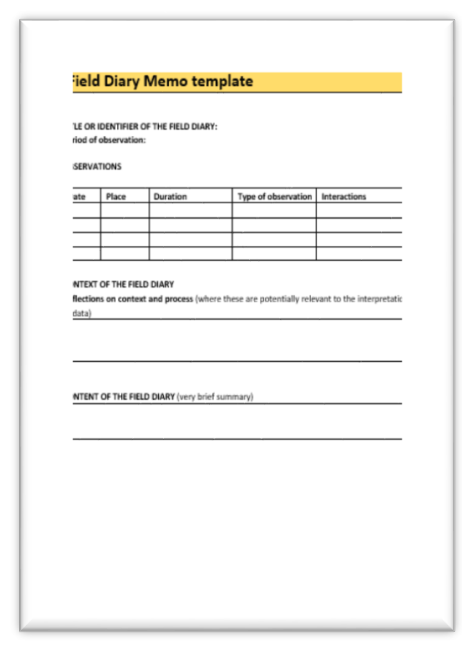

A single text file must be entered into NVivo for each Field Diary that will contain observations from different days and, possibly, different places and activities. The investigator must decide if each case study contains a single Field Diary or several, depending on the content of the observations. At the time of encoding the field diaries, using NVivo, researchers will encode mainly the descriptive observations. The personal thoughts and reflections of the researcher are the material that should feature in these Fieldwork Diary Memos. 


\subsubsection{Node Memos: Sharing the encoding}

The Node Memos are the fundamental instrument on which the idea of bringing meanings in the coding process in the framework of an international project is based. These are reports what help us to understand how the coding process has occurred in each case study and that detail the meaning of the codes as interpretive raw material, according to the context, circumstances and peculiarities of each case study. In addition, because they will be written entirely in English, they will allow direct access to translated first-level code citations, thus facilitating direct connection to fieldwork data.

The Node Memos are made on the second level codes (level 2 nodes). There is no Node Memos to do for the first level codes. Each case study (NVivo project) has to make a Node Memo for each of the second level codes. This means that each NVivo project has to have a report of how the second level codes have been developed.

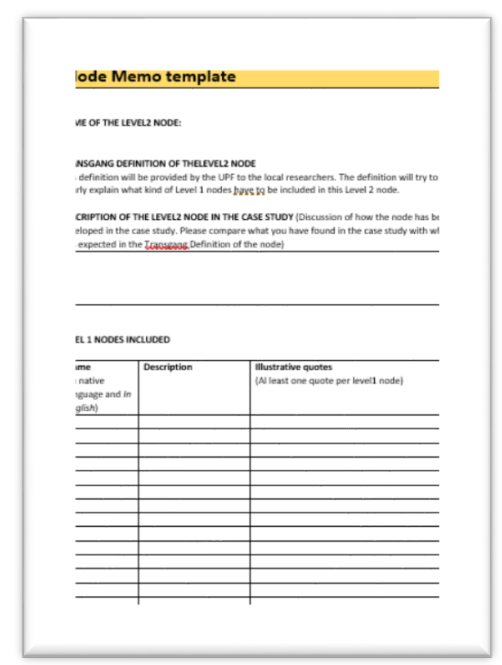

In TRANSGANG for each project / case study, a node memo must be made for all second level codes that appear in the case. As indicated in the template of the Node Memos (Appendix 2), it is necessary to specify how the second level code has appeared in said case study, indicating in particular if there is any variation or nuance with respect to the common explanation for the whole project of this code. Next, the node memos include a table where all the 1 st level codes linked to the 2nd level code of the node memo are presented, with a description and an example of a quote in English for each code.

[STEP 3] Implications for teams of local researchers

Core Cities (3):

- 16 Respondent memos:

- 6 Focus Group Memos 
- 3 Field Diary Memo

- 60-90 Node memos (considering between 20 and $302 n$ level codes)

\section{Contrast Cities (8):}

- 8 Respondent memos:

- 3 Focus Group Memos

- 2-3 Field Diary Memo

- 40-90 Node memos (considering between 20 and $302 \mathrm{n}$ level codes)

\subsection{Step 4: Data interpretation and reporting}

As indicated in the Concept Paper and in the methodological section of this document, TRANSGANG's analysis will be carried out at three levels: local, regional and transnational. These documents give more details on the type of analysis and the objectives of the resulting reports, which will be complemented by a guide and templates that the coordinating team will send to local researchers in due course for the preparation of these reports. The objective of this section is only to give a first idea of the final use of the data, the coding and the memos as an instrument for analysis.

At the local level, ethnographic reports prepared by local researchers should include an analysis of the different case studies ( 3 for core cities and 1 for contrast cities). In the process of preparing ethnographic reports, the use of encoding with NVivo represents a very useful tool to quickly and systematically access primary data. Researchers will be able to use 1st and 2nd level codes (level 1 and level 2 nodes) and direct quotes of coded texts and files in a straightforward way. Linking with the $2^{\text {nd }}$ level code clusters can facilitate the organization of primary information based on these analytical dimensions, which is one of the reporting requirements. As explained above, Nvivo allows attribute profiles of the informants to documents. This possibility is very useful at the time of analysis because it allows organizing the information based on these previously defined attributes. For example, differentiate codes and quotes based on the gender of the informant, age, belonging to certain groups, etc. Nvivo also offers many other possibilities of analysis from the entered primary data that can complement the classic ethnographic report. These instruments can be used optionally and in a complementary way by local researchers. It is important to emphasize that all these facilities and potentials offered by the program should be a tool to facilitate the organization and analysis of the data, but they cannot substitute the interpretive and analytical role of the researcher. Reports must include contextual and interpretive information that is not obtained or organized through any computer software. This analytical dimension is essential and should be the one that guides all data analysis.

In the regional report and transnational report all the work of organization, systematization and coding of primary data through Nvivo and the Memos strategy 
offers the option of accessing primary data and knowing in a direct and comprehensive way the meanings and interpretations of the coding process. These meta-ethnographic reports will be carried out, first of all, through an in-depth reading of the local ethnographic reports prepared by the local researchers and through direct knowledge of the ethnographic visits. In addition, thanks to the strategy proposed in this document, the regional ethnographic coordinators and the IP, in charge of preparing these reports, will be able to access the primary documents in an orderly and systematic way. The Nvivo coding system will allow access, for example, to direct quotes according to $1^{\text {st }}$ level codes, with highly contextualized and unique meanings of the cases, without losing information. It will also allow seeing how the information has been organized in the different case studies, through the $1^{\text {st }}$ and $2^{\text {nd }}$ level codes. In this sense, the coding analysis tools and texts that Nvivo offers can be a very useful resource. Memos also acquire their full value for meta-ethnographic analysis. The memos of the interviews, life stories, discussion groups and field diaries will serve to better understand the process of ethnographic work and to resort to the contextualization of a specific data. Node memos are of fundamental importance in making the interpretive process that constitutes codification understandable. In the Node Memos, the contextualized meaning of 2 nd level codes and their development in the field is registered. This is essential information for comparing ethnographic research.

The entire strategy proposed in this document is aimed at facilitating the organization and systematization of data at different levels of research. But also to produce resources to minimize the possible loss of information and contextualized meanings that a metaethnographic investigation inevitably faces.

[STEP 4] (Minimal) implications for teams of local researchers

Core cities (3):

- 1 local ethnographic report including all the cases (3)

Contrast cities (9):

- 1 local ethnographic report

\subsection{Step 5: Archiving and sharing of data, memos and reports}

The result of the field work will be three types of documents: the original documents with the primary data (complete transcripts and field diaries following the ethnography templates); the memos (result of the analysis of these documents with Nvivo); and local ethnographic reports (where these data will be synthesized, placing them into context). Once written, all these documents, following TRANSGANG's ethical protocols, will be uploaded to the shared dropbox folder (TRANSGANG_Data) in each of the three 
regions (Europe -EU-, North Africa -AFR-, America -AME- ), to which local researchers, the regional ethnographic coordinator, the scientific coordinator and the principal investigator will have access.

Appendix 4 describes in detail, following the example of Barcelona, both the content of the Dropbox shared data folders and the way in which the different files should be saved. To do this, all the existing content of folder division is explained in detail according to the different investigation techniques used. There is a specific folder for each city (within the most general folder of each region). This Appendix should serve as a guide to save the data extracted from the field work.

$\Rightarrow$ The explanation of the process for sharing data, memos and reports can be found in Appendix 4 (TRANSGANG Dropbox).

Finally, in Appendix 5 you can find the complete list with all the documents, templates and files related to the fieldwork that must be followed to save all the data.

$\Rightarrow$ The list with all the necessary documents for the field work can be found in Appendix 5 (TRANSGANG Toolkit). 


\section{References}

Abel, T. 1947. The Nature and Use of Biograms. American Journal of Sociology, 53: 111-8.

Agar M. (1996). The Professional Stranger: An Informal Introduction to Ethnography. New York: Academic Press.

Bakhtin, M. (1981). The Dialogic Imagination: Four Essays. Austin: University of Texas Press.

Bauer, M. (1996). The narrative interview: Comments on a technique of qualitative data collection. Papers in Social Research Methods - Qualitative Series, Vol. 1. London: London School of Economics, Methodology Institute.

Bernard H. (1988) Research Methods in Cultural Anthropology. Newbury Park: Sage.

Britten, N., CampbellL, R., Pope, C., Donovan, J., Morgan, M. and Pill, R. (2002) Using meta ethnography to synthesise qualitative research: a worked example. Journal of Health Services Research \& Policy, 7 (4): 209-215

Burawoy, M. (1998). The Extended Case Method. Sociological Theory, 16(1), 4-33. https://doi.org/10.1111/0735-2751.00040

Buroway, M. (2009). The Extended Case Method: Four Countries, Four Methods, Four Great Transformations, and One Theoretical Tradition. Berkeley: University of California Press.

Butters, S. (2014). La lógica de investigación de la observación participante. En Hall, S. and Jefferson (eds.) Rituales de resistencia. Subculturas juveniles en la Gran Bretaña de postguerra. Madrid: Traficantes de sueños.

Byers, P., \& Wilcox, J. (1991). Focus groups: A qualitative opportunity for researchers. Journal of Business Communication 28 (1), 63-78.

Callejo J. (2001). Invitación a la práctica del análisis e interpretación de una transcripción de grupo de discusión. En Callejo, J. El grupo de discusión: introducción a una práctica de investigación. Barcelona: Ariel, (pp. 193-253).

Feixa, C. (2019). La imaginación autobiográfica. Las historias de vida como instrumento de investigación. Barcelona: Gedisa.

Ferrarotti, F. (1981). Storia e storie di vita. Bari: Laterza.

Flick, U. (1998). An Introduction to Qualitative Research. London: Sage.

Goldkuhl, G and Cronholm, S (2010) Adding Theoretical Grounding to Grounded Theory: Toward MultiGrounded Theory. International Journal of Qualitative Methods 9(2): 187-205.

Hammersley, M. and Atkinson, P. (1995) Ethnography: Principles in Practice. London: Routledge.

Krueger, R.A. (1988). Focus Groups: A Practical Guide for Applied Research. Newbury Park: SAGE Publications.

Langness, L. \& Frank, G. (1985). Lives. An Anthropological Approach to Biography, Novato: Chandler \& Sharp

Lewis, O. 1964 (1971). Los hijos de Sánchez. Mexico: Moritz.

Marcus, G. E. (1995) Ethnography in/of the World System: The Emergence of Multi-Sited Ethnography. Annual Review of Anthropology 24: 95-117.

Morgan, D. (1997). Focus Group as a Qualitative Method. In Focus Groups as Qualitative Research. London: Sage, QRMS 16, 7-17.

Noblit, G. W. and Dwight Hare, R. (1988). Meta-Ethnography: Synthesizing Qualitative Studies, Newbury Park: Sage

O’Reilly, K. (2005): Ethnographic Methods. London: Routledge.

Pilkington, H. (2018). Employing meta-ethnography in the analysis of qualitative data sets on youth activism: a new tool for transnational research projects? Qualitative Research, 18(1), 108-13.

Pujadas, J.J. (1992). El método biográfico: el uso de las historias de vida en Ciencias Sociales. Madrid: CIS.

Schütz, A. (1974a [1962]). El problema de la realidad social. Buenos Aires: Amorrortu. 
Schütz, A. (1974b [1964]). Estudios sobre teoría social. Buenos Aires: Amorrortu.

Schütze, F. (2005). Cognitive Figures of Autobiographical Extempore Narration. In Miller, R.s (eds.), Biographical Research Methods, vol. II, London: Sage, (pp. 289-338).

Silverman, D. (1994). Interpreting qualitative data. London: Sage.

Stake R. (2000). The Case Study Method in Social Inquiry. In Gomm, R., Hammersley, M., Foster P., (eds.) Case Study Method. London: Sage, (pp. 19-26).

Szczepanski, J. (1978). El método biográfico. Papers, 10: 229-256.

Thomas, W.I. \& Znaniecki, F. (1978). The Polish Peasant in Europe and America. New York: Dover.

Vallés, M. (1997) Técnicas cualitativas de investigación social. Reflexión metodológica y práctica profesional. Madrid: Síntesis.

Znaniecki, F. (1972). On Humanistic Sociology. Chicago: Chicago University Press. 


\section{Appendices}




\subsection{TRANSGANG Templates}

Template 1a: Members Interview

General Data

\begin{tabular}{|l|l|}
\hline Code of Interview & CITY_INT_MEM_01_YY-MM-DD \\
\hline
\end{tabular}

\section{Interview Data}

\begin{tabular}{|l|l|}
\hline Name of the Interviewer(s) & \\
\hline Place & \\
\hline Date(s) & \\
\hline Hour & \\
\hline Duration & \\
\hline
\end{tabular}

\section{Personal Data}

\begin{tabular}{|l|l|}
\hline Code & CITY_MEM_01 \\
\hline Gender & \\
\hline Age & \\
\hline Citizenship & \\
\hline Place of birth (City-Village) & \\
\hline Place of Residence (City-Area) & \\
\hline Education (Higher Title Achieved) & \\
\hline Occupation (Present job or activity) & \\
\hline Father's Profession (Only young) & \\
\hline Mother's Profession (Only young) & \\
\hline Age of migration (if relevant) & \\
\hline Age of arrival to the city (if diferent) & \\
\hline $\begin{array}{l}\text { Membership of youth street groups } \\
\text { associations }\end{array}$ & \\
\hline Age of entry in youth street group & \\
\hline Present position in youth street group & \\
\hline Other Relevant Data & \\
\hline
\end{tabular}

\section{Context Data:}

Short description about the context of the interview (250-500 words)

\section{Summary:}

Synthesis of the main topics and ideas of the interview, organized according to clusters (1000-1500 words)

\section{Literal transcription of the interview in English or Spanish}

Ex:

- INTERVIEWER: Please, could you tell me some experience about....

My name is ... I was born in.... 
Template 1b: Stakeholders Interview

\section{General Data}

Code of Interview

\section{Interview Data}

\begin{tabular}{|l|l|}
\hline Name of the Interviewer(s) & \\
\hline Place & \\
\hline Date(s) & \\
\hline Hour & \\
\hline Duration & \\
\hline
\end{tabular}

\section{Personal Data}

\begin{tabular}{|l|l|}
\hline Code & CITY_STK_01 \\
\hline Gender & \\
\hline Age & \\
\hline Professional position & \\
\hline Institution & \\
\hline Years of experience in the institution & \\
\hline
\end{tabular}

\section{Context Data}

Short description about the context of the interview (250-500 words)

\section{Summary}

Synthesis of the main topics and ideas of the interview, organized according to clusters (1000-1500 words)

\section{Literal transcription of the interview (in the original language)}

Ex:

- INTERVIEWER: Please, could you tell me some experience about....

My name is ... I was born in.... 


\section{Template 2: Focus Groups}

General Data

Code

\section{Focus Group Data}

Name of Interviewer

Place

Date

Hour

Duration

\section{Participants Data (One per participant)}

\begin{tabular}{|l|l|}
\hline MEMBER 1 & CITY_MEM_01 \\
\hline Gender & \\
\hline Age & \\
\hline Citizenship & \\
\hline Place of birth (City-Village) & \\
\hline Place of Residence (City-Area) & \\
\hline Education (Higher Title Achieved) & \\
\hline Occupation (Present job or activity) & \\
\hline Membership of Street Groups/ Associations & \\
\hline Year of migration (if relevant) & \\
\hline Year of arrival to the city (if different) & \\
\hline Other Relevant Data & \\
\hline
\end{tabular}

\begin{tabular}{|l|l|}
\hline STAKEHOLDER 1 & CITY_STK_01 \\
\hline Gender & \\
\hline Age & \\
\hline Professional position & \\
\hline Institution & \\
\hline Years of experience in the institution & \\
\hline Other Relevant Data & \\
\hline
\end{tabular}

\section{Context Data}

Short description about the place where the focus group has been developed and the development of it (250-500 words)

\section{Summary}

Summary of main topics and ideas of the focus group, organized according to clusters (1000-1500 words)

\section{Literal transcription of the Focus Group (in the original language)}

Ex:

INTERVIEWER: The first question is

CODE1: I agree with you because.

(she needs some time to think the answer).

CODE2: In my opinion... 


\section{Template 3: Life Stories}

\section{General Data}

Code of Interview

\section{Interview Data}

\begin{tabular}{|l|l|}
\hline Name of the Interviewer(s) & \\
\hline Place & \\
\hline Date(s) & \\
\hline Hour & \\
\hline Duration & \\
\hline
\end{tabular}

\section{Personal Data}

\begin{tabular}{|l|l|}
\hline Code & CITY_MEM_01 \\
\hline Gender & \\
\hline Age & \\
\hline Citizenship & \\
\hline Place of birth (City-Village) & \\
\hline Place of Residence (City-Area) & \\
\hline Education (Higher Title Achieved) & \\
\hline Occupation (Present job or activity) & \\
\hline Father's Profession (Only young) & \\
\hline Mother's Profession (Only young) & \\
\hline Age of migration (if relevant) & \\
\hline Age of arrival to the city (if diferent) & \\
\hline $\begin{array}{l}\text { Membership of youth street groups } \\
\text { associations }\end{array}$ & \\
\hline Age of entry in youth street group & \\
\hline Present position in youth street group & \\
\hline Other Relevant Data & \\
\hline
\end{tabular}

\section{Context Data}

Short description about the context of the interview (250-500 words)

\section{Summary}

Synthesis of the main topics and ideas of the interview, organized according to clusters (10001500 words)

\section{Literal transcription of the interview (in the original language)}

Ex:

- INTERVIEWER: Please, could you tell me some experience about....

My name is ... I was born in.... 


\section{Template 4: Observation}

\section{Observation Data}

\begin{tabular}{|l|l|}
\hline Code & CITY_OP_YY-MM-DD \\
\hline Name of the observer & \\
\hline Place & \\
\hline Date(s) & \\
\hline Hour & \\
\hline Special characteristic of the day & \\
\hline Duration & \\
\hline
\end{tabular}

\section{Field Notes}

\begin{tabular}{|c|c|c|c|c|}
\hline $\begin{array}{c}\text { Hours of } \\
\text { observation }\end{array}$ & Place & People & Actions & Commentaries \\
\hline $10.00-11.00$ & & & & \\
\hline $11.00-12.00$ & & & & \\
\hline $12.00-13.00$ & & & & \\
\hline
\end{tabular}

\section{Thick description of observation (6000-8000 words)}

Summary of main topics and ideas of the observation, organized according to clusters.

\section{Template 5: Ethnographic Visits}

\section{Travel Data}

\begin{tabular}{|l|l|}
\hline Name of the observer & \\
\hline Country & \\
\hline Dates & \\
\hline City & \\
\hline Neighboorhood & \\
\hline Duration & \\
\hline
\end{tabular}

\section{Field Notes}

Summary of Field Notes.

Thick description of observation (6000-8000 words)

Summary of main topics and ideas of the observation, organized according to clusters. 


\subsection{TRANSGANG Codebook}

\begin{tabular}{|c|c|c|c|c|}
\hline Level 3 & Level 2 & Level 1 & Dimension & Definition \\
\hline CLUSTERS & GENERAL NODES & LOCAL NODES & & \\
\hline Frameworks & Categories & Examples & & \\
\hline \multirow[t]{2}{*}{$\begin{array}{l}\text { General frameworks to } \\
\text { decode data } \\
\text { (etic perspective) }\end{array}$} & $\begin{array}{l}\text { General categories to } \\
\text { encode data } \\
\text { (etic perspective) }\end{array}$ & $\begin{array}{l}\text { Native categories to encode data } \\
\text { (emic perspective) }\end{array}$ & $\begin{array}{l}\text { P: Person } \\
\text { G: Group } \\
\text { S: Society }\end{array}$ & \\
\hline & $\begin{array}{l}\text { UPF Team } \\
\text { (English) }\end{array}$ & $\begin{array}{l}\text { Local Researchers } \\
\text { (Native language) }\end{array}$ & & \\
\hline \multirow[t]{2}{*}{ 0. BIOGRAPHY } & & & & $\begin{array}{l}\text { Specific biographical information not present in the clusters, in particular } \\
\text { those that define the family and social background and the moments of } \\
\text { change in the life course }\end{array}$ \\
\hline & 0. Biography & $\begin{array}{l}\text { Personal background, evolution, crisis, } \\
\text { failure, success }\end{array}$ & $\mathrm{P}$ & Family and social background, personal turning points. \\
\hline \multirow[t]{6}{*}{ I. ORGANIZATION } & & & & $\begin{array}{l}\text { Forms of internal organization of the group that substantiate its history, } \\
\text { structure and functions. Includes structure and agency (at a group level), } \\
\text { group entry, membership and exit procedures (at individual level) }\end{array}$ \\
\hline & 1. History & Foundation, evolution, present & $\mathrm{G}$ & $\begin{array}{l}\text { Historical origins of the group in its geographical framework and evolution } \\
\text { to the present. }\end{array}$ \\
\hline & 2. $\quad$ Structure & Leadership, positions, membership & $\mathrm{G}$ & Vertical and horizontal structures that give cohesion to the group \\
\hline & 3. Agency & Rules, meetings, activities, celebrations & $\mathrm{G}$ & Formal and informal activities of the group, with some regularity \\
\hline & 4. Engagement & $\begin{array}{l}\text { Preconditions, initiation, phases, social } \\
\text { condition }\end{array}$ & P S & $\begin{array}{l}\text { Forms of incorporation into the group and phases through which and } \\
\text { individual passes }\end{array}$ \\
\hline & 5. Disengagement & Exit, punishments, ex-members, motivations & P S & Forms of formal or informal detachment from the group at individual level \\
\hline \multirow[t]{4}{*}{$\begin{array}{l}\text { II } \\
\text { IDENTIFICATIONS }\end{array}$} & & & & $\begin{array}{l}\text { Forms of subjective identification of the individual in relation to the group } \\
\text { and the community; identity elements that convey the feeling of belonging to } \\
\text { the group }\end{array}$ \\
\hline & 6. Self-presentation & $\begin{array}{l}\text { Personal, group, social, ethnic, national, } \\
\text { religious identities }\end{array}$ & $P G$ & Narratives of self-presentation at personal and group level \\
\hline & 7. Territory & Street, neighbourhood, city downtown & P G & $\begin{array}{l}\text { Identification with the territorial environment: street-corner, public spaces, } \\
\text { neighbourhood, the city, the country... }\end{array}$ \\
\hline & 8. Aesthetics & Dress, hair, body, tattoo, group aesthetics & $P G$ & Identification with material elements for the presentation of the self \\
\hline
\end{tabular}




\begin{tabular}{|c|c|c|c|c|}
\hline & 9. Music and arts & Music and arts & $\mathrm{PG}$ & Identification with music and artistic styles and practices \\
\hline & 10. Language & Slang, gestures, emoticons, tags & $\mathrm{PG}$ & Verbal and non-verbal forms of communication \\
\hline \multirow[t]{7}{*}{ III. PRACTICES } & & & & $\begin{array}{l}\text { Ordinary and extraordinary activities of the members of the youth street } \\
\text { groups }\end{array}$ \\
\hline & 11. Education & $\begin{array}{l}\text { School, training, non-formal education, } \\
\text { group training }\end{array}$ & $\mathrm{PG}$ & $\begin{array}{l}\text { Experiences of formal, non-formal and informal education at individual level } \\
\text { and also at a group level (transmission of the group values) }\end{array}$ \\
\hline & 12. Economies & $\begin{array}{l}\text { Job, informal economy, group economic } \\
\text { activities }\end{array}$ & $P G$ & $\begin{array}{l}\text { Experiences of formal and informal work; legal, not legal and illegal ways of } \\
\text { earning money. }\end{array}$ \\
\hline & 13. Leisure & Sport, dance, hobbies, promenades & $\mathrm{PG}$ & $\begin{array}{l}\text { Use of the leisure time, commercial and not commercial, online and offline, } \\
\text { including the experience of « doing nothing » }\end{array}$ \\
\hline & 14. Social media & Uses of internet, social networks, streaming & $\mathrm{PG}$ & Information relevant for the Research on Social Media \\
\hline & 15. Deviance & Delinquency, fights, violence & PG & $\begin{array}{l}\text { Experiences of outlaw behaviour; violence exercised or suffered; illegal but } \\
\text { legitimate practices }\end{array}$ \\
\hline & 16. Resistance & Activism, protest, demonstrations & $\mathrm{PG}$ & $\begin{array}{l}\text { Experiences of participation in pro-social activities, in defence of the group } \\
\text { or the community }\end{array}$ \\
\hline \multirow[t]{7}{*}{ IV. RELATIONS } & & & & $\begin{array}{l}\text { Social relations of members of street youth groups, both internal and external } \\
\text { (with other groups, with adults, with the state and with society civil) }\end{array}$ \\
\hline & 17. Insiders & Friendship, brotherhood, gendered & $\mathrm{G}$ & Relations inside the group (vertical and horizontal) \\
\hline & 18. Outsiders & Alliances, conflicts, coexistence & $\mathrm{G}$ & Relations with other youth street groups (alliances and opposition) \\
\hline & 19. Intergenerational & Family, Neighbours, Mentors, teachers & $\mathrm{PG}$ & Relations with adults \\
\hline & 20. Civil society & $\begin{array}{l}\text { NGOs, churches, brotherhoods (tariqas), } \\
\text { associations }\end{array}$ & GS & Relations with persons, communities or institutions of the civil society \\
\hline & 21. Authorities & Politicians, police, justice, prison & PGS & Relations with the right hand of the State: authorities and criminal system \\
\hline & 22. Social services & Social workers, care, youth centres & PGS & Relations with the left hand of the State: social services, health services \\
\hline \multirow[t]{6}{*}{ V. IMAGINARIES } & & & & $\begin{array}{l}\text { Symbolic elements that convey the personal and group identity of the } \\
\text { members of street youth groups }\end{array}$ \\
\hline & $\begin{array}{l}\text { 23. Media } \\
\text { representation }\end{array}$ & Mass media, television, press, stigmatization & $\mathrm{S}$ & Information relevant for the Research on Media Representation \\
\hline & 24. Symbols & Gestures, colours, flags, myths & G & $\begin{array}{l}\text { Symbolic elements that convey the identity of the street youth groups; myths } \\
\text { and legends }\end{array}$ \\
\hline & 25. Values & Literature, values & $\mathrm{G}$ & Values of the street youth groups: oral or written, declared or hidden \\
\hline & 26. Spiritualities & Rituals, Beliefs, celebrations & G & $\begin{array}{l}\text { Religious or spiritual feelings of the members of groups, ad individual and } \\
\text { group level, including syncretic beliefs and practices; participation in rituals }\end{array}$ \\
\hline & 27. Future & Objectives, Future, No Future & $\mathrm{G}$ & Vision of the future at personal, group and community levels \\
\hline
\end{tabular}




\begin{tabular}{|l|l|l|l|l|}
\hline VI. TRANSVERSAL & & & & $\begin{array}{l}\text { Information transversal to all the clusters, for the three key concepts of the } \\
\text { project (gang, transnationality, mediation), for the gender perspective and for } \\
\text { the impact of COVID-19 }\end{array}$ \\
\hline & 28. Gangs & $\begin{array}{l}\text { Criminal: Banda, Mara, Combo, Baltagi } \\
\text { Leisure: Organization, Hiphop, hooligans } \\
\text { Mixed: Pandilla, Parche, Hittiste, street } \\
\text { vendors }\end{array}$ & G S & $\begin{array}{l}\text { Definitions of Gang and Youth Street Groups in each location: } \\
\text { self-representations (internal) and hetero-representations (external) }\end{array}$ \\
\hline & 29. Transnationality & $\begin{array}{l}\text { Migration, deportation, expansion, } \\
\text { digitalization }\end{array}$ & P G S & $\begin{array}{l}\text { Information relevant from a transnational perspective: globalization of youth } \\
\text { street groups organization, identifications, activities and imaginaries }\end{array}$ \\
\hline & 30. Mediation & $\begin{array}{l}\text { Conflict resolution, gang truces, cock battle, } \\
\text { intercultural mediation }\end{array}$ & G S & $\begin{array}{l}\text { Experiences of formal and informal mediation, inside the group, between } \\
\text { groups and between groups and authorities }\end{array}$ \\
\hline & 31. Gender & Gender roles, love, sexuality, marriage & P G S & Information relevant from a gender perspective \\
\hline & 32. Public policies & $\begin{array}{l}\text { Local and national public policies, good } \\
\text { practices }\end{array}$ & S & Information relevant for the White Paper on Gang Public Policies \\
\hline & 33. COVID-19 & $\begin{array}{l}\text { Confinement and deconfinement at home, in } \\
\text { institutions, in prison }\end{array}$ & P G S & $\begin{array}{l}\text { Impact of coronavirus in everyday life at personal and group level: during } \\
\text { and after confinement, at home and in the streets }\end{array}$ \\
\hline & A4. Research & Empathy, suspicion, cooperation & P G & Attitudes towards the research process and to the interview; ethical aspects \\
\hline
\end{tabular}




\section{Explanation}

The codes listed above provide a skeleton for the coding tree that will be used to encode and decode the interviews, focus groups and field notes (using NVivo) from each location and case study. It is composed by 3 levels: a) shared clusters (Level 3) that will be used for the meta-ethnography comparison by the regional coordinators and UPF team; b) shared general nodes (Level 2) that will be used as the starting point for the coding tree used in each case; c) particular local nodes (Level 1) that will be proposed by Local Researchers.

The 7 Level 3 clusters are not directly encoded but used in the final comparative analysis. 5 of them are thematic, based on the global frameworks in the life of the members of street youth groups agreed in the Kick-off meeting (organization, identification, practices, relations, imaginaries). The cluster 0 includes specific biographic information of each respondent. The cluster 6 includes transversal aspects of the whole research: the 3 key concepts of the project (gang, transnational, mediation) and 3 cross-cutting aspects (gender, COVID-19 and reactions to the research).

The 34 general nodes are not exhaustive but tray to integrate all the aspects to be investigated. We expect that alongside these common Level 2 Nodes (which we anticipate will be generated naturally in all cases), additional Level 2 family nodes will emerge while you are coding. These more case-specific Level 2 nodes can simply be added to your case. For the sake of consistency, it would be helpful to name these Level 2 nodes in English. We also distinguish the dimension of the data claimed: personal, group and societal (even if of course most nodes are mixed)

A number undetermined of Level 1 local nodes will be generated directly by local researchers from the data texts through a standard process of open coding and retain, as far as possible, respondents own expressions. For this reason, Level 1 nodes will be in the original language of the interview. In this skeleton we only anticipate examples of these local codes.

Normally when coding, these Level 1 nodes are generated first and then grouped through a process of axial coding. In TRANSGANG we will work more or less in this standard way. We are simply asking you, when generating your Level 1 nodes, to group them under a number of shared Level 2 nodes if they logically fit there. Even if usually each Level 1 node will be allocated in one single level 2 node, some level 1 nodes can refer to two or more level 2 nodes. In that case, you can assign those level 1 nodes to as much level 2 nodes as necessary. This will help us significantly when we conduct the cross-case (cluster) analysis. Where the Level 1 nodes do not fit the (finally agreed) list of shared Level 2 nodes, they should be generated anyway and grouped into casespecific Level 2 nodes.

See TRANSGANG Data Handbook for a full description of the coding strategy and practice we will use in the project. 


\subsection{TRANSGANG Memos}

\section{Interview Memo template}

TRANSGANG

NAME (anonymized):

Date of the interview:

Place:

SOCIODEMOGRAPHIC PROFILE

Attributes (table exported from NVivo attributes or interview sociodemographic questions)

Other not covered relevant aspects

Other not covered relevant aspects CONTEXT OF THE INTERVIEW
Reflections on interview context and process (where these are potentially relevant to
the interpretation of data)

Anything else deemed relevant not recorded elsewhere

CONTENT OF THE INTERVIEW (very brief summary) 


\section{Life Story Memo template}

TRANSGANG

NAME (anonymized):

Interviews:

\begin{tabular}{|l|l|l|}
\hline Date & Length & Place \\
\hline & & \\
\hline & & \\
\hline & & \\
\hline & & \\
\hline
\end{tabular}

SOCIODEMOGRAPHIC PROFILE

Attributes (table exported from NVivo attributes or interview sociodemographic questions)

Other not covered relevant aspects

\section{CONTEXT OF THE INTERVIEWS}

Reflections on interviews context and process (where these are potentially relevant to the interpretation of data)

Anything else deemed relevant not recorded elsewhere

CONTENT OF THE LIFE STORY (very brief summary) 


\section{Focus Group Memo template}

TRANSGANG

TITLE OR IDENTIFIER OF THE FG:

Date of the FG:

Place:

COMPOSITION OF THE FG

Participants

\begin{tabular}{|l|l|l|}
\hline Name & Role & Main attributes (gender, age, other relevant aspects) \\
\hline & & \\
\hline & & \\
\hline & & \\
\hline & & \\
\hline
\end{tabular}

CONTEXT OF THE FG

Reflections on the focus group context and process (where these are potentially relevant to the interpretation of data)

Anything else deemed relevant not recorded elsewhere

CONTENT OF THE FG (very brief summary) 


\section{Field Diary Memo template}

\section{TRANSGANG}

TITLE OR IDENTIFIER OF THE FIELD DIARY:

Period of observation:

OBSERVATIONS

\begin{tabular}{|l|l|l|l|l|}
\hline Date & Place & Duration & Type of observation & Interactions \\
\hline & & & & \\
\hline & & & & \\
\hline & & & & \\
\hline & & & & \\
\hline
\end{tabular}

CONTEXT OF THE FIELD DIARY

Reflections on context and process (where these are potentially relevant to the interpretation of data)

CONTENT OF THE FIELD DIARY (very brief summary) 


\section{Node Memo template}

TRANSGANG

NAME OF THE LEVEL2 NODE:

TRANSGANG DEFINITION OF THE LEVEL2 NODE

This definition will be provided by the UPF to the local researchers. The definition will try to clearly explain what kind of Level 1 nodes have to be included in this Level 2 node.

DESCRIPTION OF THE LEVEL2 NODE IN THE CASE STUDY (Discussion of how the node has been developed in the case study. Please compare what you have found in the case study with what was expected in the TRANSGANG Definition of the node)

\section{LEVEL 1 NODES INCLUDED}

\begin{tabular}{|l|l|l|}
\hline $\begin{array}{l}\text { Name } \\
\text { (In native } \\
\text { language and In } \\
\text { English) }\end{array}$ & Description & $\begin{array}{l}\text { Illustrative quotes } \\
\text { (Al least one quote per levell node) }\end{array}$ \\
\hline & & \\
\hline & & \\
\hline & & \\
\hline & & \\
\hline & & \\
\hline & & \\
\hline & & \\
\hline & & \\
\hline & & \\
\hline & & \\
\hline & & \\
\hline & & \\
\hline
\end{tabular}




\subsection{TRANSGANG Dropbox Data Location and Saving Process}

\subsubsection{Dropbox Data Location}

Data from anonymised transcripts of interviews, focus groups, and life stories, along with observation tabs, should be saved in the TRANSGANG_Data folder of the shared Dropbox. For this, the present document has two purposes. On the one hand, explain the structure of the "TRANSGANG_Data_Region" folder and the different subfolders it contains. On the other hand, give some basic indications on the process of saving documents. For this, screenshots of the Dropbox will be used, always following the example of BCN. As you will see, the folder "TRANSGANG_Data" ("AFR", "AME" and "EUR") corresponding to your region will be shared with you. Each region folder contains a folder for each city (always with the abbreviation of the city: "ALG", "CAS" and "TUN" for North Africa; "CHI", "CUB", "MED" and "SAL" for the Americas, and "BCN", "MAD", "MAR" and "MIL" for Southern Europe). There is also a "0" folder for each region. This folder will be managed by the ethnographic coordinator of the region. The main issue is to always have your data in the folder referring to your city. Thus, we will not create confusion with the other LRs.

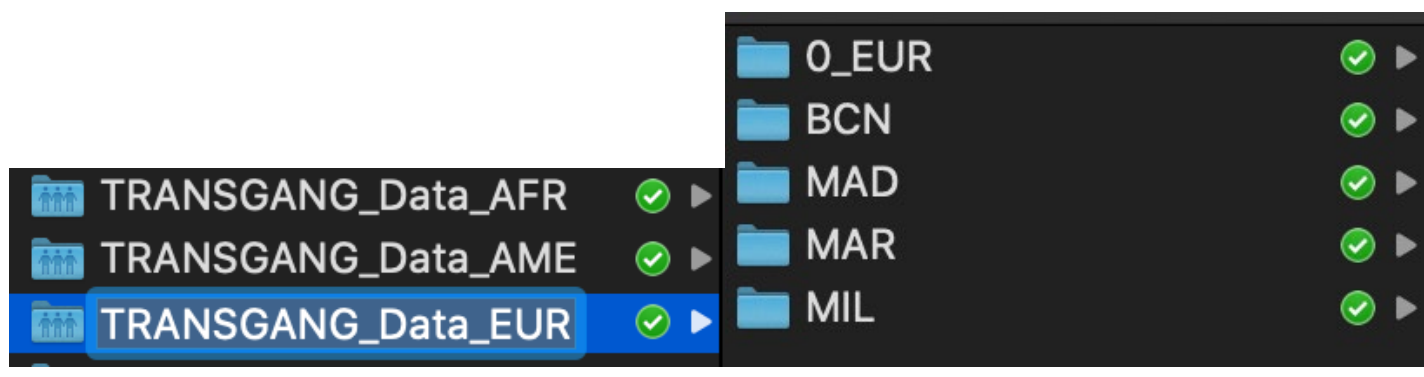

Step 1: from regions to cities

Once you are in the folder of your city, you will find 4 more subfolders. These 4 folders are divided according to the main data that will come out of your fieldwork: "Focus Groups", "Interviews", "Life Stories" and "Observations".

\begin{tabular}{|c|c|c|c|}
\hline O_EUR & $\odot \triangleright$ & Focus_Groups & $\ominus \triangleright$ \\
\hline $\mathrm{BCN}$ & ( ) & Interviews & $\odot$ \\
\hline$\square$ MAD & ( ) $\triangleright$ & Life_Stories & \\
\hline$\square$ MAR & $\odot \triangleright$ & Observations & \\
\hline MIL & $\bullet \triangleright$ & & \\
\hline
\end{tabular}

Step 2: from cities to types of data

In turn, these folders also have internal divisions to make their use more practical and facilitate the order of the data. Therefore, the "Focus_Groups" folder and the "Interviews" folder are divided, internally, into two new folders: "MEM" and "STK". This differentiation is based on the two profiles of project agents: members of street youth groups and stakeholders. 


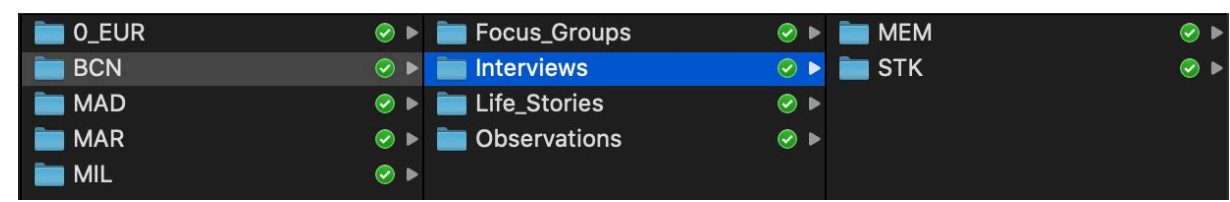

Step 3: from types of data to types of agents

The "Life_Stories" folder does not have any internal division. This research technique will only be used with young people (therefore, with MEM). Finally, the "Observations" folder has an internal division by years ("2019", "2020" and "2021"). We propose this division to order the observations by the years of fieldwork. Even so, we also propose that you order it internally in the way that best helps you (for example, within the years, by geography, neighbourhoods, groups, etc.). This is the explanation of the parts that the Dropbox contains and of the places where you must save the different documents.

\begin{tabular}{|c|c|c|c|c|c|}
\hline O_EUR & () $\triangleright$ & Focus_Groups & $0 \triangleright$ & 2019 & () \\
\hline $\mathrm{BCN}$ & (1) $\rightarrow$ & Interviews & $0>$ & 2020 & () $\triangleright$ \\
\hline MAD & $\theta>$ & Life_Stories & $0 \triangleright$ & 2021 & () - \\
\hline MAR & $0 \triangleright$ & Observations & (1) $\triangleright$ & & \\
\hline MIL & $\theta>$ & & & & \\
\hline
\end{tabular}

Step 4: Observations and years

\subsubsection{Saving Process}

The documents must have specific titles that help to order and differentiate them, as already explained in the Ethical Handbook. Next, we will make an explanatory summary through the BCN example again. The following order will always be followed: city, technique, informant, number and date.

Interviews and Focus_Groups: YOUR CITY CODE + TECHNIQUE (INT or FG) + MEM o STK + NUMBER + DATE (YEAR-MONTH-DAY). For example:

- BCN_INT_MEM_01_2019-01-08.docx

- BCN_INT_STK_01_2019-01-31.docx

- BCN_FG_MEM_01_2020-04-30.docx

- BCN_FG_STK_01_2020-04-30.docx

Life_Stories: YOUR CITY CODE + TECHNIQUE (LS) + NUMBER INTERVIEWEE - NUMBER INTERVIEW+ DATE (YEAR-MONTH-DAY). For example:

- BCN_LS_01-1_2020-04-30.docx

Observations: YOUR CITY CODE + TECHNIQUE + DATE (YEAR-MONTH-DAY). For example:

- BCN_OBS_2019-05-21-doxs 


\subsection{TRANSGANG Toolkit}

\begin{tabular}{|c|c|}
\hline $\begin{array}{l}\text { TRANSGANG Toolkit: Working } \\
\text { Documents for Local } \\
\text { Researchers }\end{array}$ & \\
\hline Document type & Document Name in Dropbox \\
\hline \multirow[b]{2}{*}{ schedule } & Working Plan General YEARS \\
\hline & TimelineTransgang \\
\hline \multirow{3}{*}{ theoretical tools } & TRANSGANG Concept Paper CAST \\
\hline & TRANSGANG Concept Paper ENG \\
\hline & TRANSGANG Comparative Clusters \\
\hline \multirow{4}{*}{ ethnographic tools } & Participants selection: Attachment $0-82$ \\
\hline & Management-risk: Attachment $0-80$ \\
\hline & TRANSGANG etnographic fieldwork handbook \\
\hline & TRANSGANG Interview guidelines \\
\hline \multirow{2}{*}{ ethnographic templates } & Focus group, Interview, Observation, Life story \\
\hline & ConsentForms : consent forms (ES, FR, EN, AR) \\
\hline \multirow{9}{*}{ ethical procedures } & Photo Reproduction Rights Form - English \\
\hline & Derechos imagen cast \\
\hline & $\underline{\text { Research Ethics and Safety Handbook - English }}$ \\
\hline & Research Ethics and Safety Handbook - CAST \\
\hline & $\begin{array}{l}\text { Visual Methods - Research Ethics and Safety Handbook ENG } \\
\text { Safety Handbook - English }\end{array}$ \\
\hline & $\begin{array}{l}\text { Visual Methods - Research Ethics and Safety Handbook } \\
\text { Safety Handbook CAST }\end{array}$ \\
\hline & $\begin{array}{l}\text { Bimonthly Fieldwork Ethics and Safety Report } \\
\text { ENG - 26-07-2019 }\end{array}$ \\
\hline & Bimonthly Fieldwork Ethics and Safety Report CAST \\
\hline & TRANSGANG Raw Data Folder- Access Instructions CAST \\
\hline
\end{tabular}




\begin{tabular}{|l|l|}
\hline & \multicolumn{1}{l}{ TRANSGANG Raw Data Folder- Access Instructions ENG } \\
\hline TRANSGANG Handbook: Ethnography and Data Analysis CAST \\
\hline TRANSGANG Handbook: Ethnography and Data Analysis ENG \\
\hline TRANSGANG Codebook \\
\hline Nvivo 12 Training Manual \\
\hline TRANSGANG Memos Templates \\
\hline TRANSGANG Toolkit: Working Documents for Local Researchers \\
\hline TRANSGANG Dropbox Data Location and Saving Process \\
\hline
\end{tabular}




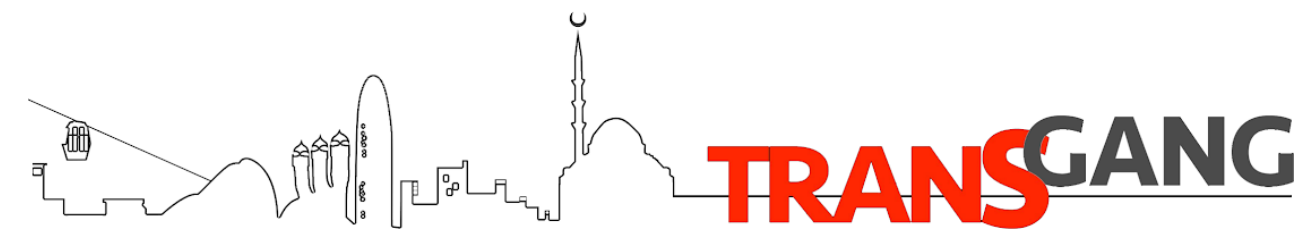

(C) TRANSGANG \& UPF

www.upf.edu/web/transgang

transgang@upf.edu.

This project has received funding from the European Research Council (ERC) under the European Union's HORIZON 2020 research and innovation programme under grant agreement No 742705

$\mathbf{u} p f$.

Universitat

Pompeu Fabra

Barcelona

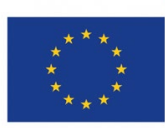

errc 